\title{
The Ming shi-lu as a Source for Thai History -- Fourteenth to Seventeenth Centuries.
}

\author{
GEOFF WADE \\ 27,337 words \\ 1 September 2000 \\ Journal of Southeast Asian Studies \\ 249 \\ ISSN: 0022-4634; Volume 31; Issue 2 \\ English
}

Copyright 2000 Gale Group Inc. All rights reserved. COPYRIGHT 2000 Singapore University Press Pte Ltd.

\section{INTRODUCTION}

The use of Chinese sources to re/construct the pasts of polities and societies which today form part of the Kingdom of Thailand is certainly not a new endeavour. [1] However, despite the attention that over the years has been given to Chinese sources for the historical study of Thailand and other Southeast Asian polities, one of the most valuable and detailed of such sources has remained little used. The Ming shi-lu ([CHINESE CHARACTERS NOT REPRODUCIBLE IN ASCII]), or "Veritable Records of the Ming Dynasty", is a collective name for the imperial annals of the Chinese Ming dynasty (1368-1644); it provides us with an invaluable resource for confirming, expanding, restructuring or revising the historical record of Southeast Asia over the period from the fourteenth to the seventeenth centuries.

The article below is based on a scanning of the entire text of the MSL, as well as of the publications noted above. It is intended to first introduce the MSL, then to outline its nature as a historical text and finally to suggest how references from this work might be used in elucidating some aspects of Thai history.

One of the major reasons the MSL has remained so infrequently used is its huge size. It is a chronological record of the activities of the Chinese court, the central government and provincial and local governments over the entire Ming dynasty and it runs to over 40,000 manuscript pages of unpunctuated classical Chinese. Given that the work is not indexed, the only way to find references of relevance to any subject of enquiry is to scan the entire text -- a not inconsiderable task. Some of the difficulties for scholars interested in Southeast Asian history were removed by the compilation and publication (in Chinese) in 1968 and 1976 of two volumes of MSL references to Southeast Asia, as well as an index to references relating to diplomatic missions from Islamic countries to China, published in 1975. [2] A number of scholars have also utilized MSL references to Thai polities in their studies. [3] More recently, a People's Republic of China publication [4] has provided an excellent classified listing (also in C hinese) of MSL references to foreign polities, including those of Southeast Asia, and this will certainly provide a fillip to scholars engaged in research on Southeast Asian history. However, the fact that the references are not as yet available in translation limits the use which can be made of them by scholars without a reading knowledge of Chinese.

\section{THE MING SHI-LU (MSL)}

Wolfgang Franke, in his Introduction to the Sources of Ming History,[5] provides a concise overview of the process of compilation and the characteristics of the various shi-lu. Essentially, each shi-lu is an account of the reign of one emperor (the Ying-zong shi-lu is an exception), compiled following his death on the basis of court diaries, audience records and the various government documents produced during his reign. The work of compilation was carried out by a History Office established for that purpose under the Grand Secretariat, and involved an editorial staff of 60 to 100 persons. On completion of the account, two copies were prepared -- one was sealed for use in the eventual writing of the dynastic history and the other was used for reference by the court and official historians. Re-editing did occur on occasions, and in one case an entire reign was excised and rewritten as an extension of the previous emperor's reign. There has, however, been extensive textual criticism of this most primary source for Ming history, and firm dates have been ascertained for the extant versions. The periods covered by the respective shi-lu and the dates of compilation are as follows:

$\begin{array}{lcll}\text { Shi-lu } & \text { Reign Title/s } & \text { Period Included } \\ \text { Tai-zu } & \text { Hong-wu } & \text { May 1351-24 Jun } 1398 \\ \text { Tai-zong } & \text { Yong-le } & 24 \text { Jun 1398-2 Sep } 1424 \\ \text { Ren-zong } & \text { Hong-xi } & 25 \text { Aug } 1424-29 \text { May } 1425 \\ \text { Xuan-zong } & \text { Xuan-de } & 16 \text { Jun 1425-31 Jan } 1435 \\ \text { Ying-zong } & \text { Zheng-tong } & 29 \text { Jan } 1435-23 \text { Feb } 1464 \\ & \text { Jing-tai } & & \\ \text { Tian-shun } & & \\ \text { Xian-zong } & \text { Cheng-hua } & 23 \text { Feb } 1464-9 \text { Sep } 1487 \\ \text { Xiao-zong } & \text { Hong-zhi } & 9 \text { Sep } 1487-8 \text { Jun } 1505 \\ \text { Wu-zong } & \text { Zheng-de } & 9 \text { Jun 1505-27 May } 1521\end{array}$




\begin{tabular}{|c|c|}
\hline Shi-zong & 27 May 1521-23 Jan 1567 \\
\hline $\mathrm{Mu}-\mathrm{zong}$ & 24 Jan 1567-5 Jul 1572 \\
\hline Shen-zong & 5 Jul 1572-18 Aug 1620 \\
\hline Guang-zong & 19 Aug $1620-25$ sep 1620 \\
\hline Xi-zong & 7 Feb 1628-24 Apr 1644 \\
\hline Shi-lu & $\begin{array}{l}\text { Date of Compilation } \\
\text { of Extant Version }\end{array}$ \\
\hline Tai-zu & 1418 \\
\hline Tai-zong & 1430 \\
\hline Ren-zong & 1430 \\
\hline Xuan-zong & 1438 \\
\hline Ying-zong & 1467 \\
\hline Xian-zong & 1491 \\
\hline Xiao-zong & 1509 \\
\hline Wu-zong & 1525 \\
\hline Shi-zong & 1577 \\
\hline $\mathrm{Mu}-\mathrm{zong}$ & 1574 \\
\hline Shen-zong & 1623 \\
\hline Guang-zong & 1623 \\
\hline Xi-zong & Late seventeenth century \\
\hline Source: Com & iled on the basis of information \\
\hline $\begin{array}{l}\text { in Franke, } \\
\text { Ming Histor }\end{array}$ & in Introduction to the sources of \\
\hline
\end{tabular}

All copies of the shi-lu were kept secreted in the Grand Secretariat until the Wan-li reign (1572-1620), when private copies began to circulate. All copies down to the twentieth century were manuscripts, allowing much potential for errors during copying. The first printed edition was published in 1940; it was a photo-lithographed copy of a manuscript held in the Jiangsu Provincial Library. This has subsequently been shown to be one of the most error-ridden manuscripts. The most widely used and recognized edition today is a photo-lithographed version compiled by the Academia Sinica in Taiwan over the years 1962 to 1966 under the direction of Huang Chang-chien. Based on the Peking Library copy, which was likely a palace copy, the compilation comprises over 130 volumes, with a further 20 volumes of textual criticism and variants, each averaging 300 pages. It is on the Taiwan edition that this article is based.

The contents of the MSL are vast and disparate. Central, provincial and local occurrences; court proceedings, incoming memorials and imperial orders despatched; natural portents; taxation details; military expeditions; personnel changes; the sending of envoys abroad and reception of foreign envoys; and all manner of other subjects of interest to the Chinese bureaucracy are recorded, often in quite full detail. References of relevance to Southeast Asia obviously constitute only a small fraction of the entries. Such references are mainly contained in the accounts of envoys being received or despatched; memorials from the border provinces such as Guangdong, Guangxi and Yunnan; and memorials from ministers relating to frontier/foreign policies.

THE MING SHI-LU AS A HISTORICAL SOURCE

Like any historical source, the MSL needs to be subjected to the usual scrutiny in order to assess the likely veracity and value of references contained therein. To assist in such assessment, a few characteristics which demonstrate the importance of this source should be noted.

Firstly, the MSL is a repository of a wide range of copied memorials and other documents, or summaries of such documents, from the various Ming reigns. It is thus more detailed in many respects than any subsequent accounts, and far more detailed that the official Ming Shi ([CHINESE CHARACTERS NOT REPRODUCIBLE IN ASCII]) or "History of the Ming Dynasty", compiled in the late seventeenth and early eighteenth 
centuries. [6] Moreover, the shi-lu were compiled not long after the end of each reign on the basis of documents from that reign, and thus the recording of events was quite close in time to the events themselves. Secondly, the accounts have extremely precise chronologies. The various shi-lu are divided by year and month, and within each juan (or chapter), by day. All entries are thus dated to a specific day, which can often be cross-checked against other sources. This verifiable chronological precision of the MSL constitutes one of its greatest strengths as a historical source.

However, there are also numerous characteristics which complicate the use of the MSL. Chinese scholars consider one of the major defects of some of the shi-lu to be the degree to which personal and clique prejudices affected compilation. Such prejudices resulted in praise and blame (major elements in official Chinese historiography) being assigned in obvious accordance with the partiality of the compilers. It is, however, difficult to assess how far such intra-court partialities affected the MSL references to Southeast Asia.

Another element which determined what was recorded in the various shi-lu was the fact that these were essentially reign records, centred on the court and the administration in the chinese capital. The further away from the court a particular area was located, the less attention was paid to it. Self-centrality is, of course, characteristic of most historical writing, and in using the MSL to examine Southeast Asian history, it is necessary to attempt to mentally "decentre" the references utilised. Such "decentring" requires some knowledge of the "Chinese world view" or at least the "Chinese world-view rhetoric" which shaped how polities beyond China were understood and represented in official historiography. The conventional "civilized/ uncivilized" dichotomy associated with the distinction between "chinese" and "other" certainly should not be ignored in examining the MSL references to polities abroad. However, there were quite a wide range of other expectations, insinuations and understandings implicit in the se references as well. It might be instructive, in trying to comprehend this "Chinese world-view rhetoric", to quote in full a reference from the year 1419, in which the Yong-le Emperor of China is noted as sending "instructions" to "San-lai Po-mo-lai-zha-di-lai" (Somdet Borommarachathirat), the "king of Siam":

An envoy was sent with instructions for San-lai Po-mo-lai-zha-di-lai, the king of the country of Siam, as follows: "I reverently took on the mandate of Heaven and I rule the chinese and the yi. In my rule, I embody Heaven and Earth's love and concern for the welfare of all things and look on all equally, without distinguishing between one and the other. You, king, have been able to respect Heaven and serve the superior and have fulfilled your tribute duties. I have been greatly pleased by this for a long time. Recently Yi-si-han-da-er Sha [= Iskander Shah], the king of the country of Melaka, inherited the throne [of Melaka]. He has been able to carry on his father's will and has personally brought his wife and children to the Court to offer tribute. This loyalty in serving the superior is no different from yours. However, I have learned that, without reason, you have intended to send troops against him. With the dangerous weapons troops carry, when two sides meet in combat, it is inevitable that there will be great injuries on both sides. Thus, those who are fond of employing troops do not have virtuous hearts. The king of the country of Melaka has already become part of "the within", and he is a minister of the court. If he has committed an offence, you should report details to the court. You must not rashly send troops on this account. If you do so, is it not the same as having no Court? Such actions will certainly not be your wishes. Perhaps it is your ministers using your name in despatching troops to pursue private quarrels. You should consider such matters deeply and not allow yourself to be deceived. If you develop good relations with neighbouring countries and do not engage in mutual aggression, the prosperity which will result will be limitless. You, king, should bear this in mind!" [7] 
This reference quite succinctly reveals certain elements of Ming China's "world-view rhetoric", the most obvious of which were:

1. The Emperor holds the mandate of Heaven ([CHINESE CHARACTERS NOT REPRODUCIBLE IN ASCII]) and thus has the divine right to rule over the Chinese and the yi ([CHINESE CHARACTERS NOT REPRODUCIBLE IN ASCII]) (non-Chinese).

2. The Emperor embodies Heaven and Earth's love for all living things. ([CHINESE CHARACTERS NOT REPRODUCIBLE IN ASCII])

3. The Emperor looks equally on all and does not differentiate between the various tributaries. ([CHINESE CHARACTERS NOT REPRODUCIBLE IN ASCII])

4. It was required of enfeoffed tributary rulers that they:

(i) Respect Heaven. ([CHINESE CHARACTERS NOT REPRODUCIBLE IN ASCII])

(ii) Serve the superior. ([CHINESE CHARACTERS NOT REPRODUCIBLE IN ASCII])

(iii) Carry out their functions and offer tribute ([CHINESE CHARACTERS NOT REPRODUCIBLE IN ASCII])

(iv) Cultivate good relations with their neighbours ([CHINESE CHARACTERS NOT REPRODUCIBLE IN ASCII])

Hidden behind the verbiage in this text, however, was the fact that at this time China was employing Melaka as a base for its massive armed forays into the Indian Ocean under eunuch commanders such as Zheng He, and there was the implication that any attempt by Siam to seize that port would result in hostilities with the Ming. Such rhetoric and idealized concepts of relations between China and the polities beyond its borders sometimes resulted in a need to adjust the MSL record for events which did not conform to the required patterns. An interesting example of such events is what I have termed the "Lin Xiao incident".

It is recorded in the MSL that on the thirteenth day of the seventh month in the eighteenth year of the Cheng-hua reign (equivalent to 28 July 1482), the Chinese court sent Lin Xiao ([CHINESE CHARACTERS NOT REPRODUCIBLE IN ASCII]) a supervising secretary in the Office of Scrutiny for Justice, as chief envoy, together with the Messenger Yao Long ([CHINESE CHARACTERS NOT REPRODUCIBLE IN ASCII]) as deputy envoy, to Siam in order to enfeoff "Guo-long Bo-la Lue-kun Si-li You-di" (Krung Phra Nakhon Si [Sri]) Ayudhya) as the king of the country. [8] Such an action by the Chinese court was of course in conformity with the elite Chinese world view of the time, whereby the court "enfeoffed" the rulers of surrounding polities, thereby obliging them to regularly offer tribute as symbolic submission. Nothing more is immediately recorded in the MSL about the mission and, on the assumption that the ruler was subsequently smoothly enfeoffed, the compilers of the Ming Shi some centuries later recorded that Lin Xiao had done so at this time. 
In the MSL record of 1505, however, we read a very cryptic statement. In an on-going debate on the appropriate method for dealing with the king of Champa, it is noted that: "In the past, when the Supervising Secretary Lin Xiao went as an envoy to Melaka, [the ruler] refused to kneel facing to the north, and [Lin Xiao] was secluded, given little food and died. We could not go to punish the crime and both the gravity of Imperial orders and the nation's dignity inevitably suffered...." [9] As there was no record of Lin Xiao ever having gone as an envoy to Melaka, the reference was sufficiently enigmatic to induce a search through the biographies of some Chinese regional gazetteers. In the Tai-ping County Gazetteer of the Jia-qing reign, a biography of Lin Xiao was found under the "Righteous and Upright Officials" section. In this biography, we read:

Lin Xiao (personal name: Ke-chong), the younger cousin of the Director [Lin] E ... Siam sent an envoy to offer tribute and advise of the death of the ruler. As Lin Xiao had clear skin and an imposing appearance, and spoke in a sonorous and clear tone, a set of first-grade robes was especially conferred upon him and, together with the Messenger Yao Long, he went to enfeoff the heir Guo-long Bo-la Lue-kun Xi-la Wu-di as king. The country lies to the South-west of Champa and the journey there requires ten days and nights with a good wind. The waves were huge and everyone on board feared the dangerous journey. Lin Xiao said: "The Emperor is Heaven. You should fear failure in carrying out the orders rather than being concerned about the dangers of the journey!" When they reached the country, there was discussion about an audience, but the rites suggested were inadequate and Lin Xiao refused to read the proclamation. They were shifted to the Western suburbs and provided with very meagre supplies. The Siamese repeat edly sought Lin Xiao's submission, but he refused to bend. His anger and indignation caused him to fall sick and he died. The deputy envoy Yao Long then humbled himself and received rich banquets and great presents. On his return the events were advised. Yao Long was dismissed and great sympathy was expressed for Lin Xiao.... [10]

Here, then, is an explanation of some aspects of the cryptic statement in the 1505 MSL reference. (It remains unclear, however, why the MSL compilers say that the events in which Lin Xiao was involved took place in Melaka.) The obviously intentional omission of the details of this incident from the MSL is very revealing in two respects. First, it suggests that the rulers of some Southeast Asian polities saw themselves as equals of or superiors to the rulers of China. Secondly, it tells us that Chinese historiographers of the Ming dynasty were very loath to record that which violated the required "patterns", failed to conform to certain modes of action and showed the chinese state being denigrated. [11] In the light of such adjustments and omissions, we would be justified in asking whether MSL references to Southeast Asian polities can be considered as useful tools in reconstructing the Southeast Asian past, or whether we should simply see them as "images" or manifestations of the ideology of the Chinese elit e. These references can in fact serve both functions, illuminating aspects of the discrete elements of the Thai past and at times informing us of the characteristics of chinese historiography and the influences and pressures which caused the historians to write in the ways they did.

This may seem an excessively long introduction to the MSL, but at least a basic understanding of the mechanisms by which this particular historical source was generated and of the ideological and rhetorical frameworks which conditioned and moulded that source is essential in assessing or re-assessing its value. 
which today fall within the Kingdom of Thailand:

Xian-luo CHINESE CHARACTER NOT REPRODUCIBLE IN ASCII or Xian-luo-hu CHINESE CHARACTER NOT REPRODUCIBLE IN ASCII = Siam

Over 200 references to this polity are found in the MSL, ranging in date from 1370 to 1623, and it is an analysis of these references which forms the basis of the present article.

Ba-bai/Da-dian CHINESE CHARACTER NOT REPRODUCIBLE IN ASCII = Lanna

The approximately seventy MSL references to the polity of "Ba-bai" (or "Ba-bai/Dadian") range in date from 1391 through the seventeenth century. Their importance as an external source against which to compare and contrast the Northern Thai chronicles is obvious, but they await a detailed examination.

Bo-le CHINESE CHARACTER NOT REPRODUCIBLE IN ASCII = Phrae? [12]

MSL references to "Bo-le" are quite sparse, and I have only been able to locate eight of them, ranging in date from 1404 to 1432 .

Da-ni CHINESE CHARACTER NOT REPRODUCIBLE IN ASCII = Patani

"Da-ni" appears quite late in the MSL record, with only a few references recorded in the sixteenth and seventeenth centuries.

Obviously, the appearance or disappearance of references to these polities from the imperial Chinese record does not necessarily indicate the appearance or disappearance of the polities per se. However, the degree of attention given by the MSL to the various polities in different periods may be suggestive of their significance in intra-Asian economic and political relations during those periods.

SIAM IN THE MSL

The Polity of Siam

As noted above, the MSL contains in excess of 200 references to a polity known as "Xian-luo" or "Xian-luo-hu". The name is widely recognized to be an amalgam of two polity names "Xian" ([CHINESE CHARACTERS NOT REPRODUCIBLE IN ASCII]) [13] and "Luo-hu" ([CHINESE CHARACTERS NOT REPRODUCIBLE IN ASCII]) [14], and the MSL appears to be the earliest extant text to make use of the combined form. [15] This polity is conventionally rendered in English as "Siam", and this convention will be followed here for references to "Xian-luo", with references to "Xian-luo-hu" being distinguished by the term "Siam (Hu)". The name "Xian-luo" is employed in the first two MSL references to Siam in 1370 and 1371. Subsequent references use either "Xian-luo" or 
"Xian-luo-hu", and during the period 1370 to 1398, "Xian-luo-hu" is used 39 times, while "Xian-luo" is used only 19 times, suggesting that the former was the more common designation at that point. A 1398 reference [16] is the final entry which uses the name "Xian-luo-hu", after which date the term ceases to appear. From then on, until the end of the Ming, all MSL references to Siam use the

name "Xian-luo".

While this obviously tells us how the Chinese state referred to this polity, the name by which its residents themselves knew it is not so obvious. We read in an early reference that in 1373 a person entitled "Can-lie Bao Pi-ya Si-li Duo-luo-lu" was "promoted by the people" to replace his nephew as ruler of Siam. [17] While the first three titles appear to be "Somdet Pu Phraya" [18], the origins of "Si-li Duo-luo-lu" are not so clear. Given that Si-li is likely "Sri" or a derivative of that honorific, I previously considered that a possible reconstruction of this name would be Sri Dvara(vati) or Si Thawara(wadi). The "Abridged Royal Chronicle" of Ayudhya [19] notes the name of the capital at its founding as "Krung Devamahanagara Pavara Dvaravati Sri Ayudhaya Mahatilakabhaba Navaratanarajadhani Puraramaya

Utamarajanivesamahasathana" while, in a study of the early names of Ayudhya [20], Prince Dhani Nivat noted that "Dvaravati" or "Thawarawadi" had formed an integral part of the name of the capital (and probabl y of the entire polity) from its earliest days. Citing the Palatine Law and letters extending as late as 1757, he concluded that "we are left with no alternative solution than that the capital was given the full name of Thawarawadi Sri Ayudhya from the time of its foundation". [21] Boeles, citing a treaty written in Thai and signed between Siam and the Netherlands in 1664 A.D., noted that at that time the capital was known as "Krung Devamahanagara Pavara Dvaravati Sri Ayudhya". [22] However, despite the possibility that "Si-li Duo-luo-lu" might have represented Sri Dvaravati, research on Ayudhyan titles increasingly suggests that it may well have been some variant of the title "Srisrindara", which occurs in the inscriptions from Tenasserim, Vat Culamani and Pichit, and in the van Vliet chronicle. Michael Vickery notes this title as being among those possibly inherited from Angkor. [23] There is thus no firm evidence from the MSL that Dvaravati/Thawarawadi (or any other name) was being used as a name for the p olity of Siam in the late fourteenth century. [24]

It is only in the middle of the fifteenth century that the toponym by which the historical polity is today best-known -- "Ayudhya" -- appears in the MSL. A reference dated to the equivalent of 3 March 1444 is the first to use the term "Gu-rong You-tixia" ([CHINESE CHARACTER NOT REPRODUCIBLE IN ASCII]) as the title of the ruler of Siam. [25] This appears to be a Chinese (probably Hokkien) [26] representation of "Krung Ayudhya" and seems to be the first reference in any Chinese source to the name "Ayudhya". In a later reference (1554), the polity's name is represented by the characters "You-chi-ya" ([CHINESE CHARACTER NOT REPRODUCIBLE IN ASCII]). [27] The MSL record thus suggests that at least by the middle of the fifteenth century, "Ayudhya" was an integral (and possibly the most important) element in the name of the polity of Siam.

Apart from the main polity of Siam, several toponyms of entities subordinate to it also occur in the MSL. A mission which arrived in the Chinese capital in 1374 was recorded as having been sent by "Zhao Lu Qun Ying" (Chao Nakhon In), the "prince of Su-men-bang" ([CHINESE CHARACTER NOT REPRODUCIBLE IN ASCII]), "heir to the king of the country of Xian-luo-hu". [28] The identification of "Su-men-bang" with Suphan(buri) seems to be universally accepted. This identity is even more obvious when the characters are read in Hokkien pronunciation -- "Soo-bbun bang". The Chinese character "bang" ([CHINESE CHARACTER NOT REPRODUCIBLE IN ASCII]) means "polity" or "territory" and thus it is probably a translation rather than a phonetic representation of the suffix "-buri". 
A year later, in 1375, another toponym enters the MSL record, when the envoy sent to China by "Zhao Bo-luo-ju" (another edition gives "Zhao Chi-luo-ju"), "the heir to the old Ming-tai prince of the country of Xian-luo-hu" ([CHINESE CHARACTER NOT REPRODUCIBLE IN ASCII]), arrived in Nanjing. [29] As in the case of Su-men-bang, the MSL recognized this polity as being part of Xian-luo-hu. The "Zhao" (= Chao) title of the heir strongly suggests that he was a Tai ruler. This must be considered in the light of a growing opinion that at this time the population of the Menam basin was possibly more Mon or Khmer in its culture. [30] Where, then, was "old Ming-tai" [CHINESE CHARACTER NOT REPRODUCIBLE IN ASCII)? Yamamoto saw this polity name as being paired with the toponym "New Men-tai" [CHINESE CHARACTER NOT REPRODUCIBLE IN ASCII] a place located at the estuary of the Menam, as detailed in the "Siam" section of Ying-yai Sheng-lan, the fifteenth-century work by Ma Huan. [31] Regardless of whether one accepts that "Men" and "Ming" represented the same indigenous word, it is quite possible that "Ming-tai" did represent the name "Muang $\mathrm{T}$ (h) ai". Could this possibly be identified with the toponym Nakhon Tai, noted in an inscription which is tentatively dated to 1397 A.D. as a polity subordinate to Sukhotai and ruled by an elder brother of the ruler of Ayudhya? [32] Nakhon Tai is also mentioned in C. S. 824 in the Luang Prasoet recension of the Ayudhyan chronicle. [33] It is interesting that the term "old" or "former" is used in the MSL reference, possibly suggesting that the "Ming-tai" polity no longer existed. Could it be a reference to the "Muang Thai" of Sukhotai itself? The absence of any MSL reference which can be unequivocally stated to refer to Sukhotai is quite remarkable.

Very little specific information is provided by the MSL on the extent of the polity of Siam or how this changed over time. One explicit mention of Siam's borders is seen in a reference of 1414, however, which notes that China's "new province" of Jiao-zhi (the term the Chinese used to refer to Dai Viet [Vietnam] subsequent to their occupation of it in 1406) bordered Siam, Laos and Champa. [34] Thus, we see in the early fifteenth century that China recognized Siam's territory as extending to Dai Viet. A further substantiating reference from the same year noted that "Siamese man" [CHINESE CHARACTER NOT REPRODUCIBLE IN ASCII] = Siamese barbarians) lived to the west of an area which Professor Yamamoto Tatsuro has suggested lay in the present Vietnamese province of Quang Tri. [35] This would place the abode of these "Siamese man" in today's southern Laos. There is no information in the MSL by which the northern, western or southern borders of Siam in any period can be ascertained. However, some idea of the range of Siam's influence in these directions can be gleaned from the references noted under "The Foreign Relations of Siam" below.

The Rulers of the Polity of Siam

The MSL, like many pre-modern histories, was inordinately concerned with political power-holders. Details of the rulers of polities which surrounded China, their heirs and acts of succession or rebellion feature prominently in the MSL. This reflected a very understandable concern of the chinese bureaucracy -- a desire to know who held power in the societies on and beyond their borders. Thus today we can use the genealogical information contained in the MSL as an additional chronology against which to compare the various chronicular traditions of the Thai and other Tai groups. Suebsaeng Promboon has argued against the chronology provided by the MSL and other Chinese sources, suggesting that Chinese recognition of rulers came several years after the actual accession, and that other "mistakes" were made by the compilers. [36] Such objections appear to derive from the fact that the chronologies of the Chinese references do not accord with the traditional Thai accounts. A closer examination of the MSL references to the successive rulers of Siam is thus in order, so that other scholars can make their own assessments as to their accuracy vis-a-vis the chronicular chronologies.

"Can-lie Zhao Pi-ya" (Sorndet Chao Phraya) 
The first ruler of the polity of Siam recorded in the MSL appears in two references at dates equivalent to October 1371 and January 1372, with the name "Can-lie Zhao Pi-ya". [37] In Hokkien pronunciation, the characters are read "Cam-liat Ziao Bi-gga". This appears to represent the title "Somdet Chao Phraya". [38]

"Can-lie Bao Pi-ya Si-li Duo-luo-lu" (Somdet Pu Phraya Srisrindara)

In December 1373, however, we read of the arrival of additional envoys from Siam and that "at this time, the king of the country of Siam, Can-lie Zhao Pi-ya, had become weak/incompetent and unable to rule CHINESE CHARACTER NOT REPRODUCIBLE IN ASCII. The people of the country thus promoted his paternal uncle 'Can-lie Bao Pi-ya Si-li Duo-luo-lu' to manage the affairs of state." [39] The suggested reconstruction of this name -- Somdet Pu Phraya Srisrindara -- has been discussed above. Suffice it here to say that, according to the Chinese annals, there appears to have been a change of ruler between 1371 and 1373 .

The sending of a mission to China by "Can-lie Si-ning", the "elder sister" of Can-lie Zhao Pi-ya, in 1373 further suggest's the possibility of contention for power among different factions at this time. [40] The Luang Prasoet (LP) Ayudhyan annals record that in C.S. 732 (1370 A.D.) Phra Ramesuan, who had only ruled for a year, was succeeded by Somdet Phra Borommarachathirat. [41] This has produced the traditional chronology of Ramesuan ruling over the period 1369/70 and Borommaracha I acceding to the throne in 1370. [42] However, the van Vliet chronicle notes of Ramesuan that "after he had reigned for three years he was deposed by his father's brother". [43] Here we have a description of an event occurring probably in 1372 or 1373, whereby a paternal uncle takes the throne of Ayudhya from his ruling nephew -- precisely what is recorded in the MSL. [44] This suggests that Can-lie Zhao Pi-ya was the ruler known as Ramesuan; that Can-lie Bao Pi-ya Si-li Duo-luo-lu was Borommaracha I, a brother of Ramathibodi; an d that Can-lie Si-ning was a daughter of Ramathibodi and an elder sister of Ramesuan. This transfer of power probably did not involve great administrative change, as the envoy "Nai Si-li Chai-la-shi-xi-ti", who had been sent by Can-lie Zhao Pi-ya and arrived in China in the equivalent of January 1372, was again despatched to the Chinese capital by the new ruler in 1373. (See Appendix I for details of Siamese envoys to the Ming court.)

"Zhao Lu Qun Ying" (Chao Nakhon In)

In 1374, the MSL mentions another obviously prominent figure in the polity of Siam, with the arrival of the envoy sent by Zhao Lu Qun Ying, the Prince of Su-men-bang and "heir to the king of the country of Siam". Grimm, with the assistance of Prince Dhani, has reconstructed this name as "Chao Nakhon In". [45] The implication that he was the son of Can-lie Bao Pi-ya Si-li Duo-luo-lu (probably Borommaracha I) is confirmed by an MSL reference from 1377, where it is noted that the father of Zhao Lu Oun Ying was the king of the country of Siam. [46] This clashes with the tradition recorded in the Abridged Royal Chronicle, which states that Prince Nagara-indra (Nakhon In) was the grandson of Borommaracha. [47] However, it conforms well to the tradition recorded in van Vliet, whereby Phra Nakhon In was the son of Chao Khun Luang Pha-ngua (Borommaracha I). [48]

"Zhao Bo-luo-ju"

Another local ruler is recorded in the MSL of late 1375, when the 
envoy sent by Zhao Bo-luo-ju (or Zhao Chi-luo-ju), who was noted as the heir to the old Ming-tai Prince, came to the Chinese court in Nanjing. [49] This is the sole MSL reference to this person and to this

polity/post. Speculation on the identity of Ming-tai is discussed above. In 1379 and 1384 there is further mention of Can-lie Bao Pi-ya Si-li Duo-luo-lu as ruler of Xian-luohu, and in 1389 Zhao Lu Qun Ying is still noted as prince of Suphan. [50] A reference in the MSL of February 1393 [51] provides the title of the ruler of Siam (Hu) at that time as only Can-lie Bao Pi-ya, but there is nothing in the intervening references to indicate that this was not the same ruler as in 1379 and 1384 . The Thai chronologies, however, suggest a maximum reign of eighteen years for Borommaracha I. [52]

"Zhao Lu Qun Yin g-duo-luo-di-la" (Chao Nakhon Intharathirat)

It was only in 1396 that the envoy sent by Zhao Lu Qun Ying, prince of Suphan, advised China of the death of Can-lie Bao Bi-ya Si-li Duo-luo-lu. [53] The Chinese court, so we are informed by the MSL, thereupon sent eunuchs to offer sacrifices for the deceased ruler and to congratulate Zhao Lu Qun Ying (his heir) on the latter's accession. [54] The next mission sent by Siam, which is noted as having arrived in January 1398, is strangely still recorded as being sent by "Zhao Lu Qun Ying, the prince of Suphan", so it may well have been despatched before the arrival of the Chinese mission sent less than a year previously. By 1403, however, Zhao Lu Qun Ying was obviously ruler of Siam in Chinese eyes, as the court sent a seal to "Zhao Lu Qun Ying-duo-luo-di-la", a title which can be reconstructed as Chao Nakhon Intharathirat. [55] This person is noted as ruler of Siam by missions arriving in China in 1404, 1406, 1408, 1410, 1411 and 1413. [56] The mission which arrived in January 1413 was the last recorded as bei ng sent by Zhao Lu Qun Ying-duo-luo-di-la.

"San-lai Bo-mo-la-zha-di-lai" (Somdet Borommarachathirat)

In May 1416, a further mission from Siam advised that the king, Zhao Lu Qun Ying Duo-luo-di-la, had died and that his son "San-lai

Bo-mo-la-zha-di-lai" (= Somdet Borommarachathirat) had "requested permission" to inherit the ruling post. [57] This ruler is noted as king of Siam in MSL references dated 1420,1421, 1422, 1424, 1426, 1427 and 1428. [58] The last MSL mention of him as ruler of Siam is seen in May 1428. [59] These references seem to correlate more closely with the Royal Autograph edition of the annals, which give Borommaracha a reign equivalent to $1418 / 19-1434 / 35$. [60]

Summing up the references until around 1430, we see the rulers of the polity of Siam as recorded by the MSL as follows:

(1.) Oct. 1371 Can-lie Zhao Pi-ya (probably Ramesuan) (replaced by his uncle, 2)

(2.) Dec. 1373 Can-lie Bao Pi-ya Si-li Duo-luo-lu (probably Borommaracha I) (paternal uncle of 1)

(3.) Feb. 1396 Zhao Lu Qun Ying Duo-luo-di-la (probably Nakhon In/Intharacha) (son of 2, former prince of Suphan) 
(4.) May 1416 San-lai Bo-mo-la-zhi-di-lai (possibly Borommaracha II) (son of 3 )

It should be obvious to those familiar with any of the Ayudhyan chronicular traditions that there is a wide variance between those chronicles and this genealogy. The MSL mentions neither a second reign for Ramesuan nor the reigns of Thonglan and Ramracha, all of which can be found in Ayudhyan sources. Perhaps more interesting is that there is no mention of maternal uncles from rival families. After Can-lie Bao Pi-ya Si-li Du-luo-lu, there is a direct succession from father to son to son. This is quite at variance with the "hi-polar" idea of competing families (from Suphanburi and Lopburi) which has grown up on the basis of the Thai chronicles. [61]

The Chinese bureaucracy certainly may not have been aware of any rivalries which existed in the siamese polity, but it would very likely have known who held demonstrable power there. The diplomatic/trade relationships between Southeast Asian and Chinese rulers were usually mediated through Chinese residing in those countries, and it is quite possible that such interlocutors depicted a "desirable" relationship (i.e., succession by a legitimate son) between a new ruler and the former one within the letters they drafted for the Thai rulers to the chinese court. Thus, while the relationship between one ruler and another may not be reflected accurately within the chinese annals, the chronology of succession is likely to be reasonably precise.

"Xi-li Ma-ha-lai" (= Si (Sri) Maharat?)

The subsequent MSL references to the rulers of Xian-luo are much less easily correlated with known names of Ayudhyan rulers. The last mention of San-lai Bo-mo-la-zhi-di-lai in 1428 may (but certainly need not necessarily) have indicated his demise within the next few years. There is no mention of his death or any other fate. It was, however, usual for the Ming annalists to maintain the same names for rulers, and a change of name within the annals (even if that name was simply a title) often indicated a change of ruler in a polity. In a reference of october 1433, we read of the recent arrival in China of an

The Ming shi-lu as a Source for Thai History

envoy who had been sent by a ruler of Siam known as "Xi-li Ma-ha-lai" (= Si [Sri] Maharat?). [62] The same name is noted for the ruler whose missions arrived in 1434 and 1438. [63] There appears nothing to connect this (or these) "Xi-li Ma-ha-lai" with any specific ruler or rulers in the chronicles. [64]

"Gu-rong You-ti-xia" (Krung Ayudhya)

In March 1444, there arrived in the Chinese capital an envoy sent by "Gu-rong You-ti-xia". [65] This title can be fairly convincingly reconstructed as "Krung (or Kurung) Ayudhya". A later reference to this mission indicates that the king had sent the envoy to memorialize that the gold-plated seal and tally reference stub-book (used to provide authentication for Siamese "tribute" missions to China) which had been previously issued to Siam had been destroyed by fire, and to request replacements. [66] While either of the major fires noted by the LP chronicle in C.S. 802 and 803 (A.D. 1440 and 1441) may have been the cause of such a "loss", the possibility of political disturbance and the 
emergence of a new ruler or polity in the mid-fifteenth century should not be discounted, particularly with this new title appearing in the MSL record. The hugely dislocated accounts given in the various editions of the Ayudhyan annals for this period further support such a conjecture. [67]

"Si-li Bo-luo-ma-na-re-zhi-la" (Sri Borommarachathirat)

A more specific title for an Ayudhyan ruler appears in April 1446, with the arrival in Beijing of a mission sent by "Si-li

Bo-luo-ma-na-re-zhi-la". [68] This name can be quite safely reconstructed as Sri Borommarachathirat. He is still noted as ruler in another reference later in that year, while in October 1447 it is recorded that, through his envoy, Si-li Bo-luo-ma-na-re-zhi-la had "surrendered the seal previously conferred". [69] The only reason that a "previously conferred" seal would have been returned to china is that a new ruler had ascended the throne and was returning that of his predecessor. We can thus be reasonably confident that there was a change of ruler in Ayudhya in the mid-1440s. As noted under "Gu-rong You-ti-xia" above, the possibility of political disturbance just prior to this period should not be ignored. The MSL thus suggests to us that someone known contemporarily as Sri Borommarachathirat was ruling Siam in the mid-1440s, and that he had come to the throne not long previously. His d eath is more firmly recorded, by a mission from Siam arriving in China in January 1453. [70]

"Ba-luo Lan-mi-sun-la" (Phra Ramesuan)

In a month equivalent to February 1453, the Chinese court sent envoys to offer sacrifices for the deceased ruler named Sri Borommarachathirat, and to enfeoff his son "Ba-luo Lan-mi-sun-la" [CHINESE CHARACTER NOT REPRODUCIBLE IN ASCII] as the "king of the country of Siam". [71] The LP version of the chronicles tells us that in C.S. 810 (1448), a prince by the name of Phra Ramesuan succeeded his father Somdet Paramarajadhiraj (Borommarachathirat) who had died that year. [72] This is apparently the situation which the MSL is describing in 1453, with the accession of Ba-luo Lan-mi-sun-la (= Phra Ramesuan), who was to become the ruler better known as Trailok. Here, we see the MSL agreeing with the LP version of the Ayudhyan chronicles, with only a few years' differential. If, as the chronicular traditions suggest, Phra Ramesuan's father was Borommaracha II, could San-lai Bo-mo-la-zha-dilai -- the son of chao Nakhon Intharathirat, recorded by the MSL as ruling in 1416 -- be the same person as Si-li Bo-luo-ma-na-re -zhi-la, who was the father of Phra Ramesuan and died some time before 1453? The MSL records no death of a ruler of Siam during the period from 1416 to 1453. The surrender of the seal mentioned in 1447 only suggests a change of ruler, but there is no detail to confirm why the seal was being replaced. [73] The chronological discrepancies for this period in the chronicular traditions have been noted by Wyatt in his annotations on the van vliet account. [74] Again, the MSL references do not fully accord with any of the versions of the Ayudhyan chronicles, but the Chinese accounts may assist researchers in future attempts to correlate and criticise the various sources on which this crucial period in Ayudhyan history is based.

"Bei-la-lan-luo-zhe-zhi-bo-zhi" (Phra Ramrachathibhodi)

In 1462, the MSL recorded the ruler of Siam as being someone by the name/title of "Bei-la-lan-luo-zhe-zhi-bo-zhi", which would appear to represent something like Phra Ramracthibhodi. [75] That some aspects of Ayudhyan life had seen continuity over the previous twenty years is suggested by the fact that Kun Pu-lun-zhi, the envoy who came to China at this time, had been sent on a previous mission in 1446 . 
"Guo-long Bo-la Lue-kun Si-li You-di" (Krung Phra Nakhon Si Ayudhya)

The arrival in July 1482 of a Siamese mission in Beijing "to request enfeoffment for their ruler" again suggests a change of ruler in the preceding few years. There is no advice of any death included in this reference, but the subsequent entry noting the sending of Chinese envoys to "enfeoff' the new king, records that the new king was the "heir" to the king of the country of Siam. [76] The name of the new ruler is of no assistance in linking these events to any in the chronicular

chronologies, as he is simply recorded as being entitled "Guo-long Bo-la Lue-kun Si-li You-di". In the reconstruction suggested by Prince Dhani, which appears to have been widely accepted, this represents "Krung Phra Nakhon Si Ayudhya". Grimm, following the chronicular traditions, suggests that the dead ruler must have been Trailok, but says that he could not have died in 1482. [77] Suebsaeng also suggests a dating error by the MSL copyists or annalists. [78]

However, in considering that the former ruler had already died, these commentators were following the Ming Ski (the standard history of the Ming dynasty completed in the early seventeenth century); the MSL itself does not mention his death. In fact, a piece of prose written by the Chinese scholar Ma Zhong-xi [CHINESE CHARACTER NOT REPRODUCIBLE IN ASCIF] (1446-1512) notes precisely the opposite. It relates to the envoy who was sent to carry out the "enfeoffment" rites for this new ruler -the Supervising Secretary Lin Xiao. [79] Following Lin's appointment as envoy to Siam, some ministers of the central administration wrote poems of encouragement for him. Ma Zhong-xi wrote the postscript to the collected poems and this is still extant. In this work, entitled "Postscript to a Collection of Poems Written on Lin Ke-chong's Appointment as an Envoy to Siam", Ma noted: "In the Ten-yin year of the Cheng-hua reign (1482/83), an envoy sent by Siam came to submit a request for enfeoffment. The Son of Heaven took pity on the king of the country who was very aged and had wearied of duties, and hastily issued orders enfeoffing his heir as king...."80

This account is quite congruent with that of van Vliet, who records that "Phra Borommatrailokanat, ninth king of Siam... ruled twenty years. He lay down his royal functions and became a religious person, to the grief of his subjects", and then "[a]fter the afore-mentioned king set down his crown, he was succeeded in the kingdom by his son, who was a young man of sixteen years". Van Vliet called the son "Phra Intharacha, the tenth king of Siam". [81] This strongly suggests that the situation described by the MSL and the other chinese texts is the formal installation of Trailok's successor in or about 1482 . The fact that the new ruler took the title "Krung Phra Nakhon Si Ayudhya" further implies that his base or capital was at Ayudhya rather than at Phitsanulok, an alternative royal seat suggested by the chronicular tradition. Could this formal installation of the new ruler have been in any way connected with the inauguration of the Phra Si Ratna Mahathat relic noted in LP as occurring in C.S. 844 (1482)? [82 ]

The "Lin Xiao Incident" of 1482, which occurred after the arrival of the Chinese envoy in Siam, has been described above. The secluding of Lin Xiao in the "western suburbs" of Ayudhya, his death and the subsequent "enfeoffing" of the ruler by the deputy Chinese envoy Yao Long were the eventual outcomes. The chinese sources quoted above suggest that differences in ritual requirements and the refusal by the ruler of Siam to "bow to the North" were the cause of the incident. However, an MSL reference dated five years later (1487) suggests something more behind the dispute: "Recently, there were differences between the language of the gold-leaf memorial by which enfeoffment was requested and the tally-slips and despatch note provided. The king suspects that the people of the country who wrote the native script have engaged in fraud." [83] Given that no other enfeoffments or envoys had 
been noted in the interim, in this reference "recently" likely refers to what occurred in 1482 or some time thereafter. This perh aps explains some of the dispute with the chinese envoy. Another "enfeoffment", unrecorded by the MSL, is possible but unlikely; such events, demonstrating the Court's functions, warranted mandatory inclusion in the annals. Guo-long Bo-la Lue-kun Xi-li You-di (-ya) is noted again as ruler of Siam in both 1491 and 1497. [84]

There follows a half-century hiatus in the MSL of specific references to Siam's rulers, with no mention of the polity at all for the period 1527 to 1553. Suebsaeng suggests that during this period palace revolts and conflict with Burma engaged all the energies of the Siamese rulers. [85] When we see Siam reappear in the MSL in 1554 and 1558, on each occasion the ruler is simply noted as "Bo Lue-kun Xi-li You-chi-ya", which represents the title Phra Nakhon Si Ayudha. [86]

Another ruler of Siam appears in the MSL in 1567. However, the various editions differ on how his name should be rendered. The standard Taiwan edition gives his name as "Hua-zhao-song" ([CHINESE CHARACTERS NOT REPRODUCIBLE IN ASCII]), while variants in other editions include "Hua-zhao-zhu" ([CHINESE CHARACTER NOT REPRODUCIBLE IN ASCII]) and "Hua-tai-song" ([CHINESE CHARACTERS NOT REPRODUCIBLE IN ASCII]). It is difficult to determine what name or title any of these might have represented. The similarity of the characters by which the three differ shows that the variants derive simply from copying errors, but the original characters cannot be ascertained. According to the MSL, the purpose of the mission which he sent to China at this time was to request a seal and tally-slips to replace those destroyed by "Dong-niu" (Toungoo). [87]

In the MSL we read of three other rulers in siam during the late sixteenth and early seventeenth centuries. In 1591 King "Niu-da-la" (presumably referring to Naresuan) is recorded as having been "required" by the Chinese to combine with Chinese troops pushing south from Yunnan in pincering the Burmese forces. [88] Someone known simply as "Pu-ai" (obviously representing phuyai, "leader" or "chief") is noted as the ruler in 1612, [89] while in 1623 the MSL records the name of the ruler of Siam as "Sen-lie Pa-la" (Somdet Phara?) [90] The references in which these names appear are all very short and there is little in the names or context to identify them with names from the chronicular record.

The Foreign Relations of the Polity of Siam

Siam and China

The foreign relations of Siam, possibly the second best-detailed aspect of this polity in the MSL, also need to be given some attention. The most important part of these foreign relations as recorded in the annals was, naturally enough, Siam's ties with China. Suebsaeng's thesis on "Sino-Siamese Tributary Relations" includes much detail on this subject, so a brief overview of the additional information provided by the MSL is all that is required.

According to the MSL, Chinese relations with Xian-luo were initiated by the Ming court's despatch of an envoy in 1370, who returned to China accompanied by a Siamese counterpart in 1371. [91] The MSL's recording of the relations with Southeast Asian polities is couched in terms of court "enfeoffment" of rulers, and of the "tribute system" by which such rulers regularly sent envoys and "tribute products" to the court to indicate their fealty. Further details of the rhetoric within which MSL references were couched are provided above. Such "tribute" missions are 
recorded throughout the MSL until the early seventeenth century; they continued after 1644 during the Qing dynasty. It is obvious from many sources that the sending of "tribute" to the court by Southeast Asian polities was only maintained as long as it was economically or politically advantageous. When there was economic benefit to be gained through the trading privileges accorded to the visiting "tribute envoys", such missions to China were very frequ ent. In consequence, there is repeated mention in the MSL of regulations being promulgated by the Chinese court, requiring that tribute be brought less frequently. [92] It is thus that the system is often referred to as a "tribute-trade" system, whereby the right to trade had the bringing of "tribute" as a prerequisite.

The essentially mercenary nature of the fifteenth-century tribute-trade system is revealed in an MSL reference of 1447, which records that the Siam envoy "Kun Pu-lun-zhi" stated that the "bowl-stone" (jadeite?) he was presenting was difficult to procure and that he sought 250 guan of paper money per jin (approximately 600 grams) for it. The Ministry of Rites noted that three years previously only 50 guan was paid per jin, and that the emperor had further reduced this price by half. A compromise on price was struck between the two parties, supposedly with the emperor making the decision. [93] The deal-making is not always so clearly depicted, but it very likely existed for all such "tribute" missions. Knowledge of the goods and products involved in the maritime trade between Ayudhya and China can also be gleaned from the MSL references. Siam provided China with aromatics and spices such as sapan-wood, laka-wood, gharu-wood, pepper and cloves; exotic animals such as elephants, peacocks, bears and white monkeys; woven goods like tula cloth [94] and rugs; decorative materials like ivory and kingfisher feathers; and sulphur, rose-water and slaves. In return, China provided silks of various types, including those interwoven with gold thread, silk gauzes and silk clothing; porcelain; medicinal materials; musk-oil; copper cash and paper money. It is not known how widely in southeast Asia Ming paper money was circulated, but envoys from most foreign polities including Siam received it as rewards, obviously in partial payment for the "tribute" goods. The paper money may all have been converted into goods before they left china.

The aromatics and spices which Siam provided to China as "tribute" were sent in huge quantities. In 1387, 10,000 jin (c. 6 tonnes) of pepper and 100,000 jin (c. 60 tonnes) of sapan-wood were brought by the envoys from Siam. [95] Again, in 1390, 171,880 jin of aromatics were taken to China. [96] This suggests that the polity of Siam had a wide-ranging network for procuring such products. Kobata Atsushi and Matsuda Mitsugu note, on the basis of Ryukyuan documents, that in early fifteenth-century Siam the government held monopolies over the trade in sapan-wood and porcelain. [97] This was likely also the case for other aromatics and exotic trade items as well. A much later reference dated 1617 shows that the trade continued into the seventeenth century, with the Siamese mission bringing 14,800 jin of "local products" to China. [98]

In 1383, China issued "tally-slips" to Siam, Champa and Cambodia, so that "when Chinese envoys arrived in future, the country could verify their status by fitting together their tally-slip with that of the envoy. If the tallies did not match, the envoy would be spurious and they were to arrest him and inform [the Ming court]." [99] A later reference in 1473 notes the issue of tally-slips and reference stub-books to Siam to "facilitate movement to and fro by the envoys". The issue of tally-slips in 1383 likely resulted from Chinese merchants passing themselves off as Ming court envoys. Despite these precautions, such activities continued, as evidenced by a 1471 reference to Qiu Hong-mm ([CHINESE CHARACTER NOT REPRODUCIBLE IN ASCII]), a person from Fujian province who sailed to Melaka to trade. On his return journey, he stopped at Siam and, claiming to be a Chinese envoy, had an audience with the ruler, while his own wife was entertained by the ruler's wife. After receiving jewels and other goods, he returned to China. Unfortunately for Qiu, the Chinese state's intelligence collection was sufficiently acute to apprehend him and ascertain what had happened. He and twenty-eight others were subsequently executed. [100] 
Genuine envoys from China were exclusively officials of the state. It appears that the Thai had a corps of "diplomat/traders", as there are instances of the same persons going to China on repeated occasions (see Appendix I). These diplomat/traders, apart from representing the Siamese polity, also appear to have operated on their own account. There were attempts by some to offer tribute on a personal basis, and references for 1457 and 1481 note that envoys visiting from Siam had privately purchased salt as well as children (presumably as slaves, potential harem inmates, or future eunuchs). [101] Those who did come regularly to China were provided with Chinese belts and headwear. In 1447, it was recorded that the headwear and filigree gold belt of "Kun Pu-lun-zhi", "the senior envoy" from the country of Siam, had not been replaced "for many years"; he received new ones that year. [102] This suggests the possibility that Kun Pu-lun-zhi was the same person as "Nai Po-lang-zhi-shi-ti", who had gone as an envoy to China in 1405 .

The size of Siamese missions to China is not always recorded, but we have details for some from the early fifteenth century. The mission which arrived in China in 1418 comprised 100 persons, and the 1420 contingent had 80, while the 1421, 1425, 1426, and 1428 missions had 60, 48, 29 and 42 persons respectively. These figures likely did not include the ship's crews, who would have remained at the port of entry. They may, however, have family members of the envoys and interpreters, as there are a number of references to mission members from Siam bringing their families to China. For example, when Nai Ai, an interpreter from Siam, lost property belonging to the king of Siam whilst in China, he fled together with his family on a ship carrying a Javanese mission. [104] The only figure available for the size of Chinese missions sent to Siam is in a 1379 reference, where it is noted that 311 officers and soldiers were rewarded after accompanying the chinese envoy. [105]

The decline in China's formal "tribute-trade" system began in the middle of the fifteenth century, and by the $1490 \mathrm{~s}$ the private trade between Guangdong and Southeast Asia appears to have far outstripped the formal, official trade. [106] Such private -- and in court eyes illegal -- trade is of course not well-documented in the imperial record. The "legal" tribute trade did continue, but with modifications. In 1559, it is obvious that the cargoes of the siamese envoys were being taxed, as they requested that the goods proportionately taxed from them be returned so that they could fund repairs to their ship. [107]

The relationship between Siam and China was not exclusively one of trade, however; there were definite symbolic and political elements involved in the visits of envoys to each other's capitals. The Lin Xiao incident detailed above shows just how important issues of national "face" were for both sides. Each Siamese mission arriving in China presented a "gold-leaf memorial" from the ruler of Siam. This was seen by the chinese as an indicator of political submission, but its significance for the Ayudhyan rulers is not known. Status was always important. When in 1503, "Pu-ba-la-zhi-cha", an official of the Palace Service Department ([CHINESE CHARACTERS NOT REPRODUCIBLE IN ASCII] -possibly some sort of office staffed by eunuchs) in Siam personally sent a despatch to China, the Ministry of Rites in Beijing considered it a major breach of protocol, noting that all previous memorials had been signed by the king. [108]

For its part, China "conferred" seals on the rulers of Siam, provided the Chinese calendar, offered "moral guidance" through works such as "Ancient and Modern Biographies of Outstanding Women", and supplied a set of standard weights and measures. [109] It also repaired or provided replacement ships to the Siamese envoys as necessary. [110] Such actions fell within the Ming elite's perceptions of China's role vis-a-vis other polities, considering itself as the centre and providing instruction, standards and assistance to all those who surrounded it. The gift of red 
dragon-robes to the ruler of Siam in 1480 [111] was very unusual in Ming foreign relations and suggests a relationship of some closeness.

In return for what were considered to be acts of munificence, the Chinese emperor/state required various things from Siam. In 1409, the ruler of Siam was ordered to repatriate a Chinese who had been engaged in piratical activities, which he did the following year. [112] When, following the Portuguese attack and occupation of Melaka in 1511, the latter requested assistance from China against the foreigners, China sent orders to Siam instructing it in "the righteousness of assisting those in distress", with the added implication that it should provide troops. [113] There were also proposals made in 1591 that Niu-da-la, the ruler of Siam, be required to assist in launching a pincer attack against the Burmese, with whom China was engaged in hostilities. [114] According to the MSL, some time prior to 1593, the ruler of Siam even offered his own naval forces to fight against the Japanese in Korea. [115]

The language/script differences between the polities of Siam and China obviously caused many problems in their relations. Suebsaeng has already detailed some of these. [116] An important reference in this respect is one from 1487, where it is noted that the envoys from Siam advised: "Under the former regulations, our country's native script ([CHINESE CHARACTERS NOT REPRODUCIBLE IN ASCII]) and Arabic script ([CHINESE CHARACTERS NOT REPRODUCIBLE IN ASCII]) were both used [for correspondence with China]. Recently there were differences between the language of the gold-leaf memorial by which enfeoffment was requested and the tally-slips and despatch note issued. The king suspects that the people of the country who wrote the native script have engaged in fraud." They requested that China conduct an investigation, but the Chinese court lacked persons with the necessary linguistic expertise and simply "ordered" that only Arabic script was to be used in future communications and that "difficult-to-understand native scripts" were not to be used. [117] Later references indicate, however, that the Siamese continued to use their own script in communicating with China. At the same time, the apparently wide use of Arabic does suggest that it played a major role in Asian trade and diplomacy at this time.

Siam and other Asian Polities

Siam's relations with other polities in southeast Asia are also the subject of some comment in the MSL. Some degree of amity between Siam and Cambodia in the late fourteenth century may be indicated by the fact that envoys from the two countries travelled to China together in 1373 and again in 1387. [118] This may, alternatively, have just been the result of Chinese missions going to both polities and bringing the envoys back to China together. It appears that at the end of the fourteenth century China also saw Siam as having some sort of links or at least contacts with Java, as it requested Siam to forward a Chinese court letter to the latter." [119] Trade links are also suggested by the 1445 capture by China (for an unspecified offence -- possibly private trade) of Javanese who had been trading with Siam. [120] Links between Siam and polities in the Indian Ocean are suggested by a 1403 reference stating that "Ha-zhi" (Haji) from the "Western Ocean" had come to China after hearing of it while he was in siam. [121] Some of the textiles noted in the MSL references to Siam also imply trading links with India.

Siam also obviously maintained frequent contacts with Ryukyu. In 1404, a Siamese ship which was heading for Ryukyu was blown ashore in Fujian. [122] A far more detailed account of Siam/Ryukyu relations is contained in Kobata and Matsuda's work, which covers the period from 1425 until the 1560s. Their study reproduces letters exchanged between the two polities, noting that the main exports from Siam to the islands were pepper and sapanwood, while its main imports were porcelain, silks and sulphur. [123] Given the obvious links between these two polities, it 
thus seems likely that the "Reo Kaeo" noted in the list of tributaries of Ayudhya in the Palatine Law (Kot Monthianban) represents "Ryukyu". [124]

The power which Siam projected externally and its less than harmonious relations with certain other Asian polities are also recorded in the MSL. In 1407, it is noted that Siam had pressured Pahang with a show of force and required it to hand over a Cham envoy who had been blown there by a storm. The rulers of Samudera and Melaka had also complained to China at that time that Siam had "sent troops to take away their seals and title patents which had been received from the court". [125] This suggests that at the beginning of the fifteenth century, the polity of Siam had the capacity to project its power to the bottom of the Malay Peninsula and to Sumatra. The reference translated under "The MSL as a Historical Source" above indicates that Siamese military pressure on Melaka was continuing in 1419 under the rule of Borommaracha, and if the MSL account is to be believed, in 1421 he "offered tribute of local products in contrition for the crime of having attacked Melaka". [126] The exertion of Siamese pressure on Melaka, or at least the desire of the latter's power-holders to suggest that this was the case, is further evidenced by a 1431 reference, when envoys sent by its ruler "advised that the king of their country wanted to personally come to the court and offer tribute, but had been obstructed by the king of the country of Siam. They also said that Siam had long wanted to invade their country.... They requested that the Court send persons to instruct the king of Siam to no longer oppress or mistreat their country." [127]

Champa also clearly constituted one of Siam's rivals in the early fifteenth century. Apart from the great efforts made to take into custody the envoy from Champa in the reference noted above, the friction is obvious later in the century when Siam laid plaint to china that in 1429/30 Champa had detained their tribute ships in Xinzhou, one of the major Cham ports (Vijaya, now in the Vietnamese province of Binh Dinh). Subsequently, Champa reported that one of their ships bound for Samudera had been captured by the Siamese "bandit" "Kun Xu-mo-nai". [128] Dai Viet was another polity with which siam competed and thus clashed in this period. This is at least suggested by the fact that when the Ming armies invaded in 1406, they found imprisoned there the sole surviving member of a Siamese mission to China which had been seized by the Vietnamese some time previously. [129]

There are few notices in the MSL of Siam's relations with polities to its immediate north. In 1445, it is recorded that Ba-bai/Da-dian (Lanna) had been issued with a gold warrant and tally to replace those burned by "bandit troops from the country of Siam". [130] This suggests military actions by Ayudhya in Lanna in the mid-fifteenth century and gels quite well with the LP annals, which note that the ruler of Ayudhya went on an expedition to Chiangmai in C.S. 804 (1442). [131] One and a half centuries later, the MSL recorded that Siam had joined with Meng Nai (Mong Nai) against Burma and Mu-bang (Hsienwi), and that China had sent a mission to Siam to arrange their co-ordination in the war against Burma. [132]

Titles in Siam

The importance of royal and official titles in the study of Siamese society and their role as tools in dating, verifying and comparing sources have been stressed by a number of scholars including, among others, Vickery, B.J. Terwiel, Yoneo Ishii, Georges Condominas and R.B. Jones. [133] The MSL provides a valuable aid in this respect, firstly because of its verifiable chronological precision and secondly because it is an external source, created by a culture which was unfamiliar with the titles of Siam and thereby unlikely to record anachronistic titles. We can assume with a fair degree of certainty that the titles recorded in the MSL were in use in the periods to which the references relate. A 
number of the titles mentioned for Siam are detailed below.

"Chao" [CHINESE CHARACTER NOT REPRODUCIBLE IN ASCII]

Probably one of the most identifiable Tai honorifics, the title "Chao" is glossed by Terwiel [134] as "chief, minister", used by itself for an independent ruler or as a part of compound titles, while condominas

[135] states that it represents "le maitre, le seigneur". In the MSL, this term is generally represented by the character "[CHINESE CHARACTER NOT REPRODUCIBLE IN ASCII]" or "[CHINESE CHARACTER NOT REPRODUCIBLE IN ASCII]" (both pronounced "zhao" in Mandarin and "ziao" in Hokkien). We see examples of the term used as a royal title as follows: the second title in the name of the ruler of Siam in 1373, Can-lie Zhao Piya

(Somdet Chao Phraya) [136]; the prime title in the name of the son of the king of Siam in 1374, Zhao Lu Qun Ying (Chao Nakhon In) [137]; and the prime title of the heir to the old Ming-tai prince, Zhao Bo-luo-ju (Chao...?). [138] The various envoys sent by Siam to China in 1371, 1373, 1378, 1384 and 1386 also bore the title "Chao". [139] However, after 1386, it appears that no more envoys w ith that title were sent to China. During this period, the use of the title may have been limited to royalty. The MSL references to the use of "Chao" in Siam are restricted to the fourteenth century, and only one reference gives us any idea of its relative status vis-a-vis other titles. In 1375, it was noted that in the Siamese mission which was in China at that time, "Zhao Zhan-duo-luo" (Chao Chandra?) was deputy to "Po Kun Gang-xin". [140] We can thus suggest that the title "Pho Khun" (see below) was superior to that of "Chao" in the Siam of the late fourteenth century.

"Khun" [CHINESE CHARACTER NOT REPRODUCIBLE IN ASCII]

Jones considers that the title "Khun" was taken into Thai from Khmer, while Vickery suggests that it was borrowed by Cambodia from Ayudhya and is probably an "old Thai term". [141] Condominas feels that it was borrowed from the Chinese term for prince or ruler -- "jun" ([CHINESE CHARACTER NOT REPRODUCIBLE IN ASCII]). [142] I have scanned references to more than thirty Tai and other Southeast Asian polities recorded in the MSL, and have found definite use of the title "Khun" (represented apparently exclusively by the character "[CHINESE CHARACTER NOT REPRODUCIBLE IN ASCII]", which is pronounced "kun" in both Mandarin and Hokkien) only in the references to Cambodia and Siam; it is particularly prominent for the latter case. Many of the envoys from Siam to China between the fourteenth and sixteenth centuries bore this title, as can be seen in the listing presented in Appendix 1. In fifteenth-century Siam, the title appears to have been superior to the title "Nai".

There are only two MSL references to Cambodia which contain likely references to "Khun". Cambodian envoys to the Chinese court in 1380 [143] and 1406 [144] are identified as "Kun Ming-zhao" ([CHINESE CHARACTER NOT REPRODUCIBLE IN ASCII]) and "Kun Si-li Ren-nong-la" (Khun Sri ....?) respectively. In addition, in the MSL references to Lan Xang and Che-li (Sipsong Panna), four envoys to China apparently bearing the title "Hun" ([CHINESE CHARACTER NOT REPRODUCIBLE IN ASCII]) are recorded. The Lao envoy to China in 1405, for example, was recorded as "Hun Dian" ([CHINESE CHARACTER NOT REPRODUCIBLE IN ASCII]). [145] This "hun" may be a variant of "Khun", but there is no firm proof of this. Given the MSL data, which suggests use of the title almost exclusively in Siam and Cambodia over the fourteenth to sixteenth centuries, if the term did derive from the Chinese "jun" ([CHINESE CHARACTER NOT REPRODUCIBLE IN ASCII]) (pronounced "gun" in Hokkien) as suggested by Condominas, it would have had to be a maritime import.

"Somdet/Samtec/Samtac" [CHINESE CHARACTER NOT REPRODUCIBLE IN ASCII] 
It is noted by Philip Jenner and Saveros Pou that "Samtac" ("Somdet" in Thai) is recorded in Khmer from at least the ninth century, with the meaning of "highness, majesty, lord". [146] In the MSL, the title is represented by the two characters "[CHINESE CHARACTER NOT REPRODUCIBLE IN ASCII]" (read "Can-lie" in Mandarin and "Cam-liat" in Hokkien). Due to the variant dialect pronunciations of the characters and the current limited understanding of how these changed over time, it is difficult to reconstruct the precise Chinese rendering of the Siamese title as it would have sounded in the fourteenth century. The term was used in the names Can-lie Zhao Pi-ya (Somdet Chao Phraya), the ruler of Siam in 1371, and "Can-lie Si-ning" (Somdet...?), the elder sister of the Siamese ruler in 1373; and in the title Can-lie Bao Pi-ya Si-li Duo-luo-lu (Somdet Pu Phraya Srisrindara?), the ruler of Siam in 1384. [147]

These three fourteenth-century references are the only examples of "Somdet" in the MSL references to Siam. Concerning the title used in the 1371 example, Vickery has drawn attention to the use of "Samtec cau brana (Somdet chao phraya) in Inscription No. 40 of Sukhothai and in a 1426 inscription from Nan, while the MSL records the title of the ruler of Cambodia in 1414 as "Can-lie zhao Ping-ya" (Somdet Chao Phraya). [148] In respect of the 1384 example, it is perhaps also important to note that the MSL records the title of the ruler of Cambodia in 1387 as "Can-lie Bao Pi-ye Gan-bu-zhe" (Somdet Pu Phraya Kambuja), and in 1404 as "Can-lie Po Pi-ya" (probably the same person). [149]

"Phraya/Brahya/Phajaa/Phrajaa/Bana/Brana" [CHINESE CHARACTER NOT REPRODUCIBLE IN ASCII]

H.L. Shorto has provided details of the use of "Bana" in Mon inscriptions. [150] Jones differentiated between "Phaja" (Phaya) and "Phrajaa" (Phraya), viewing the former as a borrowing from Khmer. [151] Vickery has suggested that the Mon "Bana", the "Brana" used in the title of Chiangmai rulers, the "Brana" found as a royal title in sukhothai, and the "Brahya/Phraya" of the Thai chronicles are all variants of the same title. [152] The only two MSL examples of the term for Siam are detailed in the previous section; its use in the Cambodian titles above should also be noted. The Chinese characters used for "piya" in the Siam examples are [CHINESE CHARACTER NOT REPRODUCIBLE IN ASCII]

"Phra" [CHINESE CHARACTER NOT REPRODUCIBLE IN ASCII]

G.B. McFarland's dictionary [153] notes this term as being equal to "Phya" (Phaya), a prefix denoting "royalty, holiness, honour". Griswold and Prasert gloss "Brah" (phra) as "sacred, noble" and note its multiple use in the full titles of Ayudhyan rulers. They suggest that it derives from Sanskrit "vara", while Vickery sees it as evolving from old Khmer "vrah". [154] In the MSL, the title is apparently only used (or at least only recorded) for the ruler of Siam or his progeny. It is represented variously by the graphs "Bei-la" [CHINESE CHARACTER NOT REPRODUCIBLE IN ASCII] "Ba-luo" [CHINESE CHARACTER NOT REPRODUCIBLE IN ASCII] or "Bo-la" [CHINESE CHARACTER NOT REPRODUCIBLE IN ASCII] The earliest occurrence of this title is observed is 1453, when it is used for the ruler's son Ba-luo Lan-mi-sun-la (Phra Ramesuan). [155] In 1462, it occurs in the title of the ruler Bei-la Lan-luo-zhe-zhi-bo-zhi (Phra Ramrachathirat?) . [156] A third example is seen in the name of the ruler in 1487 Guo-long Bo-la Lue-kun Xi-li Youdi-ya (Krung Phra Nakhon Si Ayudhya). [157]

"Pu" [CHINESE CHARACTER NOT REPRODUCIBLE IN ASCII] 
McFarland notes this term as meaning "paternal grandfather" and as a title of honour. [158] In the Sukhothai inscription of Wat Asokaram, dated to a year equivalent to 1399 A.D., the title "Somdet Pu brana" is recorded. In this inscription, the "Pu" means "grandfather", and is used in reference to a dead person (King Lidaiya). [159] The only example of this title which the MSL references to Siam provide is one used in respect of the ruler of Siam in 1373 -- Can-lie Bao Pi-ya (Somdet Pu Phraya). [160] In the Chinese phonetic representation, the "Pu" is represented by the character "[CHINESE CHARACTERS NOT REPRODUCIBLE IN ASCII]", which is pronounced "bao" in Mandarin and "bo" in Hokkien. This term "Pu" was also used in the Cambodian titles noted under

"Somdet/Samtec/Samtac" above.

"Pho Khun" [CHINESE CHARACTER NOT REPRODUCIBLE IN ASCII]

McFarland gives the meaning of pho as "father". [161] Terwiel notes that in sukhothai titles, "Khun" sometimes took "Pho" as a prefix. [162] The sole MSL reference to the use of "Pho" in Siamese society is also recorded in conjunction with "Khun". The envoy sent to China by the king of Siam in 1375 is recorded in the MSL as "Po Kun Gang-xin". [163] I have been unable to reconstruct the "Gang-xin" (Hokkien "gong-sin"), which is likely a personal name, but "Po Kun" ([CHINESE CHARACTER NOT REPRODUCIBLE IN ASCII]) obviously represents the title "Pho Khun".

"Nai" [CHINESE CHARACTER NOT REPRODUCIBLE IN ASCII]

"Nai" is glossed in McFarland as meaning "master, owner" and is noted as a "title of address, as mister". [164] It is obviously related to the Mon term "Nai" (master), seen in both the Mon inscriptions and in modem Mon. Shorto suggests that "Nai" is derived from Pali "Nayaka", glossed by the Pali Text Society as "leader, guide, lord". [165] The MSL contains numerous references to this title, almost all from siam. A glance at Appendix I shows that from 1372 to 1480, the majority of Siam's envoys to China bore the title "Nai"; after that date, the envoys were more generally entitled "Khun". It is worthy of particular note that during the fourteenth and most of the fifteenth century, the MSL only records this title for Siam and Cambodia, and it is only during the final years of the fifteenth century that we find examples of persons in Lan Xang and Sipsong Panna bearing the title. This may suggest that the term was first used in the south and only subsequently spread to Tai societies in the north.

"Krung" [CHINESE CHARACTER NOT REPRODUCIBLE IN ASCII]

As noted under the section on rulers above, within the MSL the ruler of Siam is referred to on several occasions as "Krung Ayudhya" or "Krung Phra Nakhon Si Ayudhya". [166] Thus, while McFarland noted this term as meaning "capital city" and Boeles recorded "Krung" as a part of the formal city or polity name of Ayudhya, it was also possibly a title of the ruler. [167] It appears very likely that the term is related to the "kurung" of pre-Angkorian Khmer, which Jenner notes as having both the meaning of "realm, kingdom, royal seat" as well as of "ruler, king". [168] It is also likely that the "Gu-long" [CHINESE CHARACTER NOT REPRODUCIBLE IN ASCII] which the Xin Tang shu (New History of the Tang Dynasty) recorded as the "surname" of the king of Funan, was the same term. 
"OK" appears in many official titles in the late Ayudhya period, but little is known of its evolution. Vickery suggests that this was a Thai title or that it was borrowed from Burma. [169] The MSL has only one example of the term, used in the combination "Ok-Khun" as the title of a Siamese envoy to China in 1612. [170] In this reference, the "Ok" is represented by "[CHINESE CHARACTER NOT REPRODUCIBLE IN ASCII]" (read "wo" in Mandarin and "ok" in Hokkien). The Ming Shi cites a fifteenth-century use of the title "Ok" in Siam, but the MSL does not verify such an early usage. Chinese sources, however, contain many examples of the use of the title in the second half of the seventeenth century. [171]

"Arya" [CHINESE CHARACTER NOT REPRODUCIBLE IN ASCII]

The term "Arya" is a general honorific in Sanskrit, with the meaning of "noble", "master" or "gentleman". In the MSL, the title is found almost exclusively in reference to Javanese envoys to China, many of whom were chinese or at least bore chinese names. In the references to Siam, only one example of this title is found: the envoy to China in 1426 is referred to as "Arya Chen Bao" ([CHINESE CHARACTER NOT REPRODUCIBLE IN ASCII]). "Chen Bao" is a Chinese name, and it is perhaps worth noting that this mission came to the Ming court with an embassy from Java, also headed by an "Arya", [172] so quite possibly Arya Chen Bao was also from Java.

Other Terms

It is perhaps appropriate to end this section on titles with the observation that there are two Tai titles which are widely observed in MSL references to other Tai polities but are not seen in the MSL references to Siam. The female title "Nang" ([CHINESE CHARACTER NOT REPRODUCIBLE IN ASCII]), so prominent in many Tai societies, is not recorded for Siam. Likewise "Dao/Thao" ([CHINESE CHARACTER NOT REPRODUCIBLE IN ASCII]), seen as a general honorific in polities ranging from Mong Mau in the west through to Sipsong Chau Tai in the east, and through Yunnan, Lanna and Laos, is not recorded in the MSL references to Siam. Of course, it is possible that these titles may have been used in Siamese society at social levels unlikely to have been recorded by the MSL.

Chinese in Siamese Society

The MSL records few details of the component elements of Siamese society, but some information can still be gleaned from the references. In particular, it is obvious that Chinese played quite a major role at least in the foreign trade of the polity. Charnvit Kasetsiri has noted several elements which suggest an influential Chinese presence in early Ayudhya. [173] The MSL contains various references to persons resident in Siam but who were originally from China. In $1497 \mathrm{Nai}$ Luo, an

interpreter for the Siamese mission, stated while in the Chinese capital that he hailed from Qingliu County in Fujian, and requested permission to visit his village on the journey back to Siam. This was permitted by the emperor. [174] In the same year, another person, Wan Yue, advised that he was originally from Jiangxi province in China but had once been blown off-course while proceeding to Hainan as a merchant. He had "ended up" in Siam, where he had served as an interpreter, and he was now requesting permission to remain in chin a in that capacity. He was allowed to stay, but the record is not clear as to whether he was taken on as an interpreter. [175] 
There are numerous other references to persons with Chinese names serving as envoys for Siam to China. In 1372, Li Qing ([CHINESE CHARACTERS NOT REPRODUCIBLE IN ASCII]) was sent to China as an envoy by Siam (Hu), and in 1381 and 1391 Chen Zi-ren ([CHINESE CHARACTERS NOT REPRODUCIBLE IN ASCII]) and Li Nai-ming ([CHINESE CHARACTERS NOT REPRODUCIBLE IN ASCII]) respectively are noted as having been sent as envoys to China by Siam. [176] In 1405, Zeng Shou-xian ([CHINESE CHARACTERS NOT REPRODUCIBLE IN ASCII]) is noted as an envoy, as was Huang Zi-shun ([CHINESE CHARACTERS NOT REPRODUCIBLE IN ASCII]) in 1427. Subsequently, few Chinese names appear in the MSL references to missions from Siam. However, as noted above, persons such as Nai Luo, although bearing a Thai title and name, hailed from China, and thus it is impossible to say whether further Chinese were sent on missions from Siam to China. An interesting reference in 1393 provides a glimpse of the process whereby children of Chinese and local parents were ass imilated into siamese society. The reference notes that the envoy sent by the ruler of Siam (Hu) was named "Li San-qi-de" ([CHINESE CHARACTERS NOT REPRODUCIBLE IN ASCII]). Here we have an example of a Chinese surname (Li), followed by a non-Chinese given name (San-qi-de, or Sam-chai-dak in Hokkien), suggesting that the person bore his chinese father's name, but had been given a personal name from his mother's culture. [177]

Such a phenomenon is further attested by some Buddhist votive tablets dating to the 1420s, found in Wat Ratburana in Ayudhya. These tablets bear on their reverse short inscriptions in Chinese script which include the names of those seeking blessings from the Buddha. The inscriptions are all headed "Great Ming" ([CHINESE CHARACTERS NOT REPRODUCIBLE IN ASCII]) (the then current Chinese dynasty). The names on some of the tablets are obviously entirely Chinese, but at least one bears the name "Chen Xu-bu-duan". "Chen" is a common Chinese surname, but the

"Xu-bu-duan" appears to represents a non-Chinese personal name. Why such tablets, offered by persons with Chinese or part-Chinese names should be found in a royal commemorative crypt in Ayudhya and why they should have been headed "Great Ming" remain topics for future research. [178]

\section{CONCLUSION}

History-writing is restricted by its sources. The greater the number of primary sources relating to particular periods or phenomena to which historians have access, the more compelling are the historical accounts which can be written. For the early period of the Ayudhyan polity, histories have long relied on the Thai, Pali and Cambodian chronicles and the van Vliet text in Dutch, which itself appears to derive from these chronicles. The Ming Shi-lu provides us with another source, invaluable in various respects, to augment the texts used to reconstruct the early history of Ayudhya.

The Ming Shi-lu possesses one of those characteristics prized by historians in their sources: the references within it are contemporary with the events which they record. It thus provides a reasonably precise chronology of what the chinese elite knew of events in Ayudhya for the period from the late fourteenth to the early seventeenth centuries. As the MSL is a record of the Chinese state, references to the polity of Siam form only an incidental part of that record and are couched in the rhetoric of the Chinese "worldview". It thus provides a view of Ayudhya moulded by prejudices quite different from those which informed the Thai, Pali and Cambodian chronicles. The approximately 200 references to Siam contained in the MSL therefore constitute one of the very few external, contemporary sources against which indigenous histories can be compared and contrasted, particularly for the period prior to the arrival of European observers.

A range of details about the early Ayudhyan polity are provided by the chinese chroniclers. The MSL records the Ayudhyan rulers whom the 
Chinese court recognised and the Ayudhyan polity's relations with China, as well as its links with Champa, Ryukyu, Melaka, Java and the Tai polities to its north. The role of the Chinese and Sino-Thai within the Ayudhyan external trading system and polity is also suggested by several of the references. A prominent example of how the MSL presents data useful for purposes of comparison with the chronicles is that of the titles recorded. By giving the full names of envoys and kings in various periods, the Ming annals provide a contemporary account of titles in use at that time for both rulers and officials.

Some even more essential issues of early Thai history are brought to the fore by the MSL references. The late appearance of the name Ayudhya in the Chinese texts raises questions, as does the lack of any definite reference to Sukhothai in these annals. These issues will not be explored here. Perhaps the most useful role which the MSL references to Ayudhya can play is that of a chronological check for the indigenous chronicles, which may possibly assist in resolving some of the disparities between the various recensions. In some instances, the chronology provided by the Ming shi-lu agrees reasonably well with the Luang Prasoet (LP) edition of the chronicles. The accession of Trailok is, for example, noted in LP as occurring in C.S. 810 (1448) and in the MSL as an event some years before 1453. For the early reigns, however, the MSL references can be most closely correlated with those provided in van Vliet. This is true, for example, of Borommaracha's usurpation of the throne from Ramesuan, where the MSL suppor ts van Vliet's contention that Borommaracha was the young man's paternal rather than maternal uncle, a point which has implications for our understanding of fourteenth-century Ayudhyan politics. [179]

The MSL and van Vliet are also in accord over Prince Nakhon In. While the Abridged Royal Chronicle states that he was the grandson of Borommaracha, the tradition recorded in van Vliet whereby he was in fact Borommaracha's son gels well with the MSL references. A second example is van Vliet's statement that Trailok retired to a monastery and was succeeded by his son Phra Intharacha, "the tenth king of Siam". This is very much consistent with the situation described by the MSL and other chinese texts relating to the formal installation of Trailok's successor in or about 1482. The greater consonance between sources from two very different traditions -- the Chinese MSL references and the genealogy contained within the Pali text Sangitiyavamsa -- leads one to conclude that Sangitiyavamsa and thus van Vliet provide a more accurate account of the genealogies of at least the first few rulers of Ayudhya.

In this overall sphere, an event most anxiously awaited is the publication of the late Richard Cushman's The Royal Chronicles of Ayutthaya, a compilation and collocation of the various recensions of the Ayudhyan annals, jointly edited with Professor David Wyatt of Cornell University and now awaiting publication in Bangkok. [180] When the Ming Shilu references can be properly compared to and contrasted with the various chronicular texts included in Cushman's work, we will certainly be in a better position to make statements about early Ayudhyan history, as well as about traditional Thai and Chinese historiographies.

This is a revised version of a paper originally presented at the Fifth International Conference on Thai Studies (London, 1993) in a session convened by Dr Dhiravat na Pombejra and entitled "Source Materials on Thai History c. 1600-1855: Reappraisals and Discoveries". The author would like to thank Charnvit Kasetsiri, Bruce Lockhart, Momoki Shiro, F.W. Mote, N.G. Owen, Sun Laichen and Michael Vickery for assistance, comments and materials.

(1.) Some of the better-known works which employ Chinese sources in examining Thai history include: Chan Hok-lam, "Xian-luo gong-shi 'Xie Wen-bin' shi-jian pou-xi" [An analysis of the incident involving the 
Wen-bin] in his Ming-dai Ren-wu yu Chuan-shuo [Essays on Ming personages and legends] (Hong Kong: Chinese University of Hong Kong, 1997), pp. 280-301; Chan Hok-lam, "Ming Cheng-hua Lin Xiao Yao Long chu-shi Xian-luo zhi mi" [The mystery of the mission to Siam by the envoys Lin Xiao and Yao Long during the Cheng-hua reign of the Ming Dynasty], Wenshi 3 (1999): 91-101; Chen Lu-fan, Whence Came the Thai Race? -- An Enquiry (Beijing: Guo-ji wen-hua chu-ban gong-si, 1990); E.T. Flood, "Sukhothai-Mongol Relations", Journal of the Siam Society' [henceforth JSS] 57, 2 (1969): 1-20; T. Grimm, "Thailand in the Light of Official Chinese Historiography: A Chapter in the History of the Ming Dynasty", JSS 49, 1 (1961): 1-20; Xie You-rong, Xian-luo Guo Zhi [An account of the country of Siam] (B angkok: Nan-hai dong-xun she, 1949); Hoshino Tatsuo, Pour une Histoire Medievale du Moyen Mdkong (Bangkok: Editions Duang Kamol, 1986); Xu Yun-qiao, Bei-da-nian Shi (A History of Patani) (Singapore, 1946); Li Dao-gang, "Can-lie Bao Bi-ya Cuan-wei wei wang" [The usurpation of the throne by Somdet Pu Brahya], Dong-nan-ya Xue-kan [Southeast Asian Studies Journal], 1 (1999): 52-57; and "Can-lie Zhao Bi-ya chung-deng wang-wei" [Somdet Chao Brahya resumes the throne], in Dong-nan-ya Xue-kan, 3 (1999): 48-53; Li Chang-fu, "Zhong-Tai Gu-dai Jiao-tong-shi kao" [A Study of the History of Ancient Communication Between China and Thailand], Nan-yang Xue-bao 1, 1 (1940): 5-12; G.H. Luce, "The Early Syam in Burma's History", JSS 46, 2 (1958): 123-214; G.H. Luce, "The Early Syam in Burma's History: A Supplement", JSS 47, 1 (1959): 59- 101; Paul Pelliot, "Deux itineraires de Chine en Inde ii la fin du VIIIe siecle", Bulletin de l'Ecole Francaise d'Extrene-Orient 4 (1904): 131-413; G.W. Skinner, Chinese Society in Thailand: An Analytical History (Ithaca: Cornell University Press, 1957); Sarasin Viraphol, Tribute and Profit: Sino-Siamese Trade 1652-1853 (Cambridge, MA: Harvard Council on East Asian Studies, 1977); Suebsaeng Promboon, "Sino-Siamese Tributary Relations: 1282-1853" (Ph.D. dissertation, University of Wisconsin, 1971); O.W. Wolters, "Chen-li-fu, a State on the Gulf of Siam at the beginning of the 13th Century", JSS 48, 2 (1960); O.W. Wolters, "The Khmer King at Basan (137 1-3) and the Restoration of the Cambodian Chronology During the Fourteenth and Fifteenth Centuries", Asia Major 12, 1 (1966): 80-84; O.W. Wolters, "Ayudhya and the Rearward Part of the World", Journal of the Royal Asiatic Society (1968): 166-78; Yamamoto Tatsuro, "Dawara-koku-ko" (A study of Dvaravati), Shirin 28, 4 (1943): 347-68; Yamamoto Tatsuro, "Thailand as it is referred to in the Da-de Nan-hai zhi at the beginning of the fourteenth century", Journal of East-West Maritime Relations 1 (1989): 47-58; and Zou Qi-yu, "Zhong-Tai guan-xi shi shang de y i-ge yi-an" [A mystery in the history of Sino-Thai relations], Li-shi Yan-jiu [Historical research], 5 (1980): 171-85. Further references, not seen by the author, include Likhit Hootrakul, The Historical Records of the Siamese-Chinese Relations, Vol. 1 (Thonburi, 1975) (noted by Zou); Chaloem Yongbunkoet, "Muang Thai ani chotmaihet Chin" [Thailand in Chinese records], Sinlapakorn, 7:2 (July 1963): 50-65 (noted by Charnvit Kasetsiri), and three articles by sugimoto Naojiro cited in Flood's bibliography. Details of many other Chinese-language articles on Thailand, which make use of Chinese sources, can be found in Index to Chinese Periodical Literature on Southeast Asia 1905-1966 (Singapore: Nanyang University Institute of Southeast Asia, 1967), vol. 2; and Austin G.W. Shu and William W.L. Wan, Twentieth Century Chinese Works on Southeast Asia: A Bibliography, (Honolulu: East-West Center, 1968). The Institute of Southeast Asian Studies of Zhong-shan University in Guangzhou, PRC has compiled a new collection of classical Chinese references to areas which are today part of Thailand, and this is to be published in the near future.

(2.) Chiu Ling-yeong et al., Ming shi-lu zhong zhi Dong-nan-ya Shi-liao [Southeast Asia in Chinese Reign Chronicles (Ming shi-lu)] ([CHINESE CHARACTERS NOT REPRODUCIBLE IN ASCII]) (Hong Kong: Hsueh-tsin Press, 1968 and 1976). This two-volume set was compiled at the University of Hong Kong over a decade by graduate students under the supervision of Professor Lo Hsiang-lin ([CHINESE CHARACTERS NOT REPRODUCIBLE IN ASCII]). Their publication certainly advanced knowledge of Southeast Asian references in the MSL, but the fact that the edition used was marred by copying mistakes and omitted many references limited its use. In 1971, Watanabe Hiroshi published an index of the MSL references to diplomatic missions to Ming China from Islamic countries. 
The work was subsequently published with an English explanation under the title "An Index of Embassies and Tribute Missions from Islamic Countries to Ming China (1368-1644) as Recorded in the Ming Shih-lu, Classified According to Geographic Area", Memoirs of the Toyo Bun ko 33 $(1975): 25-347$. This was a great boon to scholars wishing to locate MSL references to various southeast Asian polities.

(3.) Examples include: Chan Hok-lam, "Xian-luo gong-shi" and "Ming Cheng-hua Lin Xiao"; Suebsaeng, "Sino-Siamese"; Wolters, "The Khmer King" and "Ayudhya"; and Zou, "Zhong-Tai guan-xi".

(4.) Ming shi-lu lei-zuan: She-wai shi-liao juan [Classified Compilation of Ming shi-lu References: Historical References Relating to Foreign Lands] ([CHINESE CHARACTERS NOT REPRODUCIBLE IN ASCII]) (Wuhan: Wu-han chuban-she, 1991).

(5.) Wolfgang Franke, An Introduction to the Sources of Ming History (Kuala Lumpur: University of Malaya Press, 1968), pp. 1-33.

(6.) The account translated in Grimm, "Thailand in the Light", was taken from the Ming Shi.

(7.) Ming Tai-zong ski-lu, juan 217.la-b. The Ming shi-lu edition utilized for all references cited is that published by the Institute of History and Philology (Zhong-yang yan-jiu-yuan li-shi yu-yan

yan-jiu-suo) in Taipei over the years 1962 through 1966. References are cited by shi-lu, juan (chapter) and page number (e.g., Ming Tai-zu shi-lu, juan 243.3a refers to page 3 [recto] in chapter 243 of the Tai-zu Shi-lu).

(8.) Ming Xian-zong shi-lu, juan 229.4a.

(9.) Ming Wu-zong shi-lu, Juan 2.19a.

(10.) (Jia-qing) Tai-ping xian-zhi ([CHINESE CHARACTER NOT

REPRODUCIBLE IN ASCII]) (1811 A.D.), juan 39a-b. An earlier gazetteer of the Jia-jing reign Tai-ping zhi, dated 1540, includes a shorter account of Lin Xiao, under the "Martyrs" ([CHINESE CHARACTER NOT REPRODUCIBLE IN ASCII]) section. Western dates given are Julian dates to Oct 4, 1582, and subsequently Gregorian, converted from the Chinese chronology in accordance with Keith Hazelton's A Synchronic Chinese-Western Daily Calendar 1341-1661 A.D. (Minneapolis: University of Minnesota, History Dept., 1984).

(11.) "For further details of the mission led by Lin Xiao, see Chan Hok-lam, "Ming Cheng-hua Lin Xiao".

(12.) See, however, Sun Lai-chen, "The Origin of 'Bo-le' -- On the Relations Between the Kingdom of Sukhothai and the Ming Dynasty in the Early Fifteenth Century", in Proceedings of the 4th International Conference on Thai Studies, Vol. IV (Kunming, 1990), pp. 385-93. Sun argues that "Bo-le" was the kingdom of Sukhothai, or more specifically Phitsanulok. I feel, however, that "Bole" can only represent the toponym "Phrae". The MSL and other references suggest that this polity had quite 
some influence and independence in the first 30 years of the fifteenth century. Its name is given as "Moang Ble" in the 1393 pact concluded between Sukhothai and Nan (see A.B. Griswold and Prasert na Nagara, "The Pact between Sukhodaya and Nan [EHS No.3]", JSS 57,1 [1969]: 57-107, especially p. 97, n. 75). A Sukhothai inscription dated C.S. 762 (1400) records that the ruler of Si Satchanalai-Sukhothai had extended his rule to include Phrae (A.B. Griswold and Prasert na Nagara, "A Declaration of Independence and its Consequences [EHS No. 1]", JSS 56, 2 [1968]:

207-249, especially pp. 226-27). Sun's claim that the MSL reference to the "chieftain" Tu-ya (CHINESE CHARACTER NOT REPRODUCIBLE IN ASCII) (whose troops were used by Bo-le to conduct raids on Lanna in or before 1432) is an erroneous reference to Ayudhya, is certainly a possibility but is by no means proven.

(13.) The first reference to "Xian" ([CHINESE CHARACTER NOT REPRODUCIBLE IN ASCII]) in Chinese sources appears to be that contained in juan 418 of the Song Shi [History of the Song Dynasty], where in the biography of the Song loyalist Chen Yi-zhong ([CHINESE CHARACTER NOT REPRODUCIBLE IN ASCII]) it is noted: "In the 19th year of the zhi-yuan reign (1282/83), the Great Army [i.e. the Mongol forces] attacked Champa, and [Chen] Yi-zhong fled to Xian. He subsequently died in Xian." There are many subsequent references to Xian including those of envoys sent to China. For a general guide to the references, see Chen Jia-rong et al., Gu-dai Nan-hai Di-ming Hui-shi [Collected references to ancient names for places in the Southern Ocean] (Beijing: Zhong-hua shuju, 1986), pp. 843-44. Some of the Yuan dynasty references are translated in Luce, "The Early Syam...Supplement" and Flood, "Sukhothai-Mongol Relations". An important reference is found in Dao-yi Zhi-lue [Brief account of the Maritime Barbarians], where in the ac count of the "Country of Xian" it is recorded: "In the fifth month of the ji-chou year in the Zhi-zheng reign (May/June 1349), [Xian] submitted to Luo-hu." Su Ji-qing, a modern scholar who edited an annotated version of Dao-yi zhi-lue, entitled Dao-yi Zhi-lue Jiao-shi ([CHINESE CHARACTER NOT REPRODUCIBLE IN ASCII]) (Beijing: Zhong-hua shu-ju, 1981), suggests that as the author Wang Da-yuan only completed the work in the winter of the year quoted (1349/50), the date given for Xian's submission to Luo-hu is probably erroneous. He suggests as an alternative, though with little evidence, a year which corresponds to 1339/40. It should be noted in passing that the Huang Ming Si-yi Kao [A study of the barbarians in the four directions under the Ming Empire], completed in 1567, states that "During the Zhi-zheng reign of the Yuan dynasty, Xian brought Luo-hu to submission ([CHINESE CHARACTER NOT REPRODUCIBLE IN ASCII]) (See Zheng Xiao's Wu-xue Bian [A collection of my researches], juan shang, "Xian-luo" [[CHINESE CHAR ACTER NOT REPRODUCIBLE IN ASCII]].) It is difficult to assess what credence to assign to this reference which inverts the power relationship between the two polities provided in other texts. Much ink has been spent on trying to identify the location or extent of Xian. Many scholars have followed Pelliot, who identified it with Sukhothai ("Deux itineraires". p. 244). However, more recent works have cast doubt upon this identification. Yamamoto, "Thailand as it is referred" (p. 51), notes that the Canton gazetteer Da-de Nan-hai Zhi from the period 1297-1307 A.D. records that the "Country of Xian controls shang-shui su-gu-di" ([CHINESE CHARACTER NOT REPRODUCIBLE IN ASCII]). The "Shang-shui" can be considered either a place-name or simply "up river", while "Su-gu-di" is unquestionably Sukhothai. Yamamoto argues that if Xian controlled (or managed) Sukhothai, the two cannot be considered to have been equal terms. He considers that Ayudhya is the best identification for references to Xian.

(14.) The earliest extant Chinese reference to "Luo-hu" is probably that in Yun-lu Man-chao, a work dated 1206 A.D., where Luo-hu is noted, together with polities such as Cambodia and Pagan, as a producer of the jin-yan aromatic (the resin of styrax benzoin). Later references to Luo-hu are detailed in Chen Jia-rong et al., Gu-dai Nan-hai Di-ming Hui-shi, pp. 513-14. In the famous Chinese work Zhu-fan-zhi ([CHINESE CHARACTER NOT REPRODUCIBLE IN ASCII]) [An account of the various barbarians] of 1225, Luo-hu is noted as one of the dependencies of Cambodia. However by the end of the thirteenth century, it was recorded in the Da-de Nan-hai zhi (see previous note) as an independent polity along with Cambodia and Xian, but without any subordinate dependencies (Yamamoto, "Thailand as it is referred", pp. 49-50). For details of the subsequent amalgamation of Xian and Luo-hu, see the note above. It was 
Pelliot ("Deux itineraires", pp. 235-36) who first proposed the identification of Luo-hu with Lava] Lavo/Louvo/Lopburi, and no other credible alternatives have since been advanced.

(15.) While I suggest that the term "Xian-luo" first appeared in the MSL, there are also some pre-Ming works which contain the toponym. The term is only found in post-Ming editions of these works, however; no extant pre-Ming versions appear to include it, suggesting that such references are interpolations by later copyists. In the Zhen-la feng-tu ji [Account of the customs of Cambodia], Pelliot's revised translation of which was published posthumously as Memoires sur les Coutumes du Cambodge de Tcheou Ta-kouan (Paris: EFEO, 1951), it is noted that Xian-luo lay half a month's journey to the South-west of Cambodia. As the original work was completed prior to 1312, Pelliot considered the use of the term "Xian-luo" to be an anachronism (p. 98). The earliest edition of this text known today dates from 1544. Flood notes that in Chen Yi-zhong's account given in San-chao Ye-shi ([CHINESE CHARACTER NOT REPRODUCIBLE IN ASCII]) [An unofficial history of the three reigns], which is probably a Yuan work but exists only in later editions, there is an anachronistic "Xian-luo", probably the result of a later copyist's insertion ("Sukhothai-Mongol Relations", p. 244). Yamamoto Tatsuro, in his "Van-don: A Trade Port in Vietnam" (Memoirs of the Research Department of the Toyo Bunko 39 [1981]: 1--28) cites four references dating from 1149 to 1467 taken from the Vietnamese annals Dai Viet Su ky Toan thu in which it is recorded that ships from "Tiem-la" (the Vietnamese pronunciation of the characters "Xian-luo") had traded at Van don Yamamoto also suggests that these early references to the polity may result from miscopying or interpolation in later copying (pp. 1--5). Bruce Lockhart (personal communication) has informed me that in the most recent edition of the annals, published in Hanoi, the editors agree that the 1149 reference to "Tiem-la" may be an anachronism.

(16.) Ming Tai-zu shi-lu, juan 256.1a.

(17.) Ibid. juan $86.4 b-5 a$.

(18.) Michael Vickery (personal communication) suggests that the "pi-ya" was more likely "Banha" than "Brahya"; he considers the latter to be a conflation of "Prah" and "Banha". Suebsaeng, "Sino-Siamese", quotes Prince Damrong, who reconstructed the full title as "Somded Cawphraja Surinthararag", "another variant of the king's title" (p. 157). It is extremely unlikely, however, that the chinese would have used the character "bao" [CHINESE CHARACTER NOT REPRODUCIBLE IN ASCII] to represent the term "Caw/Chao".

(19.) D.K. Wyatt, trans. and ed., "The Abridged Royal Chronicle of Ayudhya of Prince Paramanuchitchinorot", JSS 61,1 (1973): 25--50; see p. 32 .

(20.) Prince Dhani Nivat, "The City of Thawarawadi Seri Ayudhya", in Selected Articles from the Siam Society Journal, Vol. 3 -- Early History and Ayudhya Period (Bangkok: Siam Society, 1953), pp. 229--35.

(21.) Ibid. p. 233.

(22.) J.J. Boeles, "The King of Sri Dvaravati and His Regalia", JSS

52,1 (1964): 99--114; see p. 112 . 
(23.) Michael Vickery, "The Khmer Inscriptions of Tenasserim: A Reinterpretation", JSS 61,1 (1973): 51--70; see pp. 56, 69; and "Review of Jeremias van Vliet, The Short History of Siam", JSS 64, 2 (1976): 207--236; see p. 224.

(24.) Vickery (personal communication) considers that "Dvaravati" was likely an ancient name for the city, as otherwise the name would not have been known in the fourteenth century.

(25.) Ming Ying-zong shi-lu, juan 113.5b.

(26.) In Hokkien, the characters are read "Gok-liong Yiu-te-ha".

(27.) Ming Shi-zong shi-lu, juan 414.8a; these characters are read "Yiu-di-ha" in Hokkien.

(28.) Ming Tai-zu shi-lu, juan 94.4b.

(29.) Ibid. juan 102.3 a.

(30.) For some opinions on the likely major cultural influences in the Menam basin in the late fourteenth century, see A.B. Griswold and Prasert na Nagara, "King Lodaiya of Sukhothai and his Contemporaries (EHS No. 10)", JSS 60,1 (1972): 21-152, particularly pp. 30-32; Michael Vickery, "Three Collections of Thai Historical Documents -- Kalpana", JSS 60,1 (1972): 402-409; Michael Vickery, "The Khmer Inscriptions of Tenasserim"; Michael Vickery, "Review of 'Thai Titles and Ranks', by Robert B. Jones", JSS 62,1 (1974): 158-73, especially p. 164; A.B. Griswold and Prasert na Nagara, "On Kingship and Society at Sukhodaya", in Change and Persistence in Thai Society, ed. G. William Skinner and A. Thomas Kirsch (Ithaca: Cornell University Press, 1975), p. 164; and Michael Vickery, "The 2/k. 125 Fragment, A Lost Chronicle of Ayutthaya", JSS 65,1 (1977): 1-80; see pp. 55-61, 79 .

(31.) Yamamoto, "Thailand as it is referred", p. 52. J.V.G. Mills, in his Ma Huan, Ying-yai Shenglan: The Overall Survey of the Ocean's Shores (1433) (Cambridge: Cambridge University Press, 1970), variously translates "New Men-tai" as both "New Strait Tower" (p. 102, n. 8) and "New Gate Tower" (p. 197, n.215).

(32.) A.B. Griswold and Prasert na Nagara, "A Law Promulgated by the King of Ayudhya in 1397 A.D. (EHS No. 4)", JSS 57,1 (1969): 109-148; see p. 129, n. 15. Vickery, however, in his "A Guide Through Some Recent Sukhothai Historiography" (JSS 66,2 [1978]: 182-246) suggests that the text does not have to be read as "brother", and that the inscription may not even refer to the ruler of Ayudhya (p. 231).

(33.) O. Frankfurter, "Events in Ayuddhya for Chulasakaraj 686-966", JSS 6 (1909): 1-21; see p. 6. The Chulasakarat (C.S.) calendar, frequently used in Thai sources, begins in the year 638 AD. 
(34.) Ming Tai-zong shi-lu, juan 152.2b.

(35.) Yamamoto Tatsuro, Annan Shi Kenkyu (Tokyo: Yamakawa, 1950), pp. 486-87; the reference is in Ming Tai-zong shi-lu, juan 147.21-b.

(36.) Suebsaeng, "Sino-Siamese Tributary Relations", pp. 156-57.

(37.) Ming Tai-zu shi-lu, Juan 68.4b and 70.la.

(38.) Somdet Chao Phraya" (Samtec Can Brana) as the title of a person, possibly ruler of Ayudhya, is attested in an inscription examined in A.B. Griswold and Prasert na Nagara, "A Pact between Uncle and Nephew (EHS No. 5)", JSS 58,1 (1970): 92.

(39.) Ming Tai-zu shi-lu, juan 86.4b-5a; the Hokkien reading for this name would be "Cam-liat Bo Bi-gga Su-li Do-lo-lok".

(40.) Ibid. Juan 86.2b-3a.

(41.) Frankfurter, "Events in Ayuddhya", p. 3.

(42.) See, for example, Charnvit Kasetsiri, The Rise of Ayudhya (Kuala Lumpur: Oxford University Press, 1976), p. 155.

(43.) Jeremias van Vliet, The Short History of the Kings of Siam, trans. Leonard Andaya, ed. David K. Wyatt (Bangkok: Siam Society, 1975), p. 60. See also Michael Vickery, "Review Article: Jeremias van Vliet".

(44.) Wyatt, in van Vliet, Short History, notes that "all other sources indicate that [Ramesuan's successor was the elder brother of Ramathibodi's queen from Suphanburi" (p. 60). Vickery, in "A New Tamnan About Ayudhya" (JSS 57, 2 [1979]: 123-86), a review article which examines Charnvit's The Rise of Ayudhya, discusses the traditional views of supposed marriage alliances between the families of Suphanburi and Lopburi and examines the veracity of the claims of such alliances (pp. 145-51). Suebsaeng, "Sino-Siamese", considers that the MSL references in this respect are erroneous, and he prefers to follow the chronicular traditions (pp. 153-60). However, the tradition recorded in van vliet, derives, according to Vickery, from the Pali version of the Ayudhyan annals known as Sangitiyavamsa. See Vickery, "Review Article: Jeremias van Vliet", p. 209; the Pali version does constitute a part of the Thai chronicular tradition. The greater consonance between two very different traditions -- the Chinese MSL references and the genealogies contained within the Pali text -- leads one to conclude that the latter (and thus van Vliet as well) provide a more accurate account of the genealogies of at least the first few rulers of Ayudhya.

(45.) Grimm, "Thailand in the Light", p. 16, n. 25; the reference is in Ming Tai-zu shi-lu, Juan 94 4b. 
(46.) Ming Tai-zu shi-lu, juan 115.2a.

(47.) Wyatt, "The Abridged Royal Chronicle", p. 35. Charnvit, citing Prince Damrong, has Intharaja (Nakhon In) as a nephew of Borommaracha I (The Rise of Ayudhya, p. 111).

(48.) Van Vliet, Short History, p. 62.

(49.) Ming Tai-zu shi-lu, Juan 102.3a; the Hokkien pronunciation is "Ziao But-lo-giok". On some unstated basis, Suebsaeng equates this local ruler with Phra Ramracha, "the heir to the former king Ramesuen" ("Sino-Siamese", p. 162).

(50.) Ming Tai-zu shi-lu, Juan 126.5b-6a (1379), 159.1a (1384), 195.2a (1389).

(51.) Ibid., Juan 224.1a.

(52.) See van Vliet, Short History, p. 61. The LP version of the chronicles also suggests a reign of 18 years (Frankfurter, "Events in Ayuddhya", pp. 3-4).

(53.) Ming Tai-zu shi-lu, juan 243.3a.

(54.) Ibid., juan 243.4b-5a.

(55.) Ming Tai-zong shi-lu, juan 17.2b.

(56.) Ibid., juan 34.3a, 52.3b, 82.6a-b, 111.1b, $121.4 \mathrm{~b}$ and $135.1 \mathrm{~b}$.

(57.) Ibid., juan 176.1a. The death of Chao Nakhon Intharathirat around 1416 gives a reign of approximately twenty years (dating from his accession in 1396), which is the length recorded in the van vliet chronicle. The main difference with van Vliet is that the MSL gives the reign period as 1396-1416, while the Dutch source suggests 1400-1420, according to the chronology given in M. Vickery, "Review Article: Jeremias van Vliet", p. 211.

(58.) Ming Tai-zong shi-lu, juan 217.1a-b, 224.2a, 236.4a, 268.1b; and Ming Xuan-zong shi-lu, juan 22.13b, 28.4b, 39.3a.

(59.) Ibid., juan 42.5b.

(60.) Van Vliet, Short History, p. 63, n. 45. 
(61.) See O.W. Walters, "The Khmer King", pp. 80-84, and Charnvit, The Rise of Ayudhya, pp. 106-114. Vickery, "Review Article: Jeremias van Vliet", pp. 231-33, criticizes this theory.

(62.) Ming Xuan-zong shi-lu, juan 106.2a.

(63.) Ibid., juan 110.10a, and Ming Ying-zong shi-lu, juan 39.7b.

(64.) Vickery has noted the probable absence of "maharaja" from the titles of the Ayudhyan polity ("Khmer Inscriptions", p. 54). These MSL references suggest that the title may have been in use in Ayudhya in the $1430 \mathrm{~s}$.

(65.) Ming Ying-zong shi-lu, juan 113.5b.

(67.) David Wyatt summarizes the "confused and complex" variations for the dates of Trailok's reign in van Vilet, Short History, p. 63, n. 47.

(68.) Ming Ying-zong ski-lu, juan 139.6b.

(69.) Ibid., juan 146.1 a and 158.8 a respectively.

(70.) Ibid. juan 224.8a.

(71.) Ibid., juan 225.1la-b.

(72.) Frankfurter, "Events in Ayuddhya", p. 5.

(73.) Ming Ying-zong shi-lu, juan 158.8a.

(74.) Van Vliet, Short History, p. 63, n. 47.

(75.) Ming Ying-zong shi-lu, juan 344.7b; this reconstruction has been suggested by Vickery (personal communication).

(76.) Ming Xian-zong shi-lu, Juan 229.4a.

(77.) Grimm, "Thailand in the Light", p. 19. n. 61; Prince Dhani's reconstruction is cited in note 63. 
(78.) Suebsaeng, "Sino-Siamese", pp. 186-87.

(79.) Ming Xian-zong shi-1u, juan 229.4a.

(80.) Ma Zhong-xi, Dong-tian wen-ji (Collected works of Ma Zhong-xi), juan 3, pp. 317b-319a, Jifu cong-shu edition [CHINESE CHARACTER NOT REPRODUCIBLE IN ASCII] [CHINESE CHARACTER NOT REPRODUCIBLE IN ASCII] [CHINESE CHARACTER NOT REPRODUCIBLE IN ASCII] [CHINESE CHARACTER NOT REPRODUCIBLE IN ASCII]3, [CHINESE CHARACTER NOT REPRODUCIBLE IN ASCII] Lin Ke-chong was the personal name of Lin Xiao. (81.) Van Vliet, Short History p. 64.

(82.) Frankfurter, "Events in Ayuddhya", p. 7.

(83.) Ming Xiao-zong shi-lu, juan 2.14b.

(84.) Ibid., juan 54.8a-b and 129.3a.

(85.) Suebsaeng, "Sino-Siamese", p. 190.

(86.) Ming Shi-zong shi-lu, juan 414.8a and 462.4b.

(87.) Ming Shen-zong shi-lu, juan 11.2a.

(88.) Ibid., juan 236.3b.

(89.) Ibid., juan $490.3 b$.

(90.) Ming Xi-zong shi-lu, Juan 31.17b; the reconstruction is suggested by Vickery (personal communication).

(91.) Ming Tai-zu shi-lu, juan 55.3a.

(92.) See, for example, ibid., juan 76.3b-4a.

(93.) Ming Ying-zong shi-lu, juan 157.8a-b.

(94.) "Tula" (Sanskrit for "cotton") appears to designate cotton fabrics from West Asia. See Fei Hsin, Hsing-ch'a Sheng-lan: the Overall 
Survey of the Star Raft, trans. J.V.G. Mills, ed. Roderich Ptak

(Wiesbaden: Harrassowitz, 1996), p. 77 note 225, for various references to such textiles.

(95.) Ming Tai-zu shi-lu, juan 183.4a.

(96.) Suebsaeng suggests that these aromatics were sent by Chao Nakhon In with a request for investiture ("Sino-Siamese", pp. 166-67). I have found no Ming source which supports such a claim.

(97.) Kobata Atsushi and Matsuda Mitsugu, Ryukyuan Relations with Korea and South Sea Countries: An Annotated Translation of Documents in the Reidai Hoan (Kyoto: Kobata Atsushi, 1969), pp. 53-64.

(98.) Ming Shen-zong shi-lu, juan 562.8a.

(99.) Ming Tai-zu shi-lu, juan 153.3a.

(100.) Ming Xian-zong shi-lu, juan 97.7b.

(101.) Ibid., juan 279.1a and 217.4a.

(102.) Ming Ying-zong shi-lu, juan 158.1b.

(103.) Ming Tai-zong shi-lu, Juan 48.1a.

(104.) Ming Ying-zong shi-lu, Juan 158.4a-b.

(105.) Ming Tai-zu shi-lu, juan 121.4b.

(106.) Ming Xiao-zong shi-lu, Juan 73.3a-b.

(107.) Ming Shi-zong shi-lu, Juan 476.3b.

(108.) Ming Xiao-zong shi-lu, juan 200.5b-6a.

(109.) See, for example, Ming Tai-zong shi-lu, juan 17.2v (seals) and $34.3 a$ (weights and measures).

(110.) Ming Xian-zong shi-lu Juan 192.3a-b. 
(111.) Ibid., juan 206.2b.

(112.) Ming Tai-zong shi-lu juan 97.1b.

(113.) Ming Shi-zong shi-lu, juan 4.27b

(114.) Ming Shen-zong shi-lu juan 236.3b.

(115.) Ibid., juan 256.1b-2a. See O.W. Wolters, "Ayudhya and the Rearward Part" for details of this incident.

(116.) Suebsaeng, "Sino-Siamese", pp 187-90, 192-93.

(117.) Ming Xiao-zong shi-lu juan 2.14b.

(118.) Ming Tai-zu shi-lu, juan 85.7b (1373) and 183.4a (1387).

(119.) Ibid., juan 254.6a-7a. See also O.W. Wolters, The Fall of Srivijaya in Malay History (Ithaca: Cornell University Press, 1970), PP. 49-71, for details of a possible scenario which might have given rise to this letter.

(120.) Ming Ying-zong shi-lu, Juan 132.8a.

(121.) Ming Tai-zong shi-lu, Juan 24.3a.

(122.) Ibid., juan 34. 1b-2a.

(123.) Kobata and Matsuda, Ryukyuan Relations, pp. 60-72; relations with Siam are covered on pp. 53-100.

(124.) D. Wyatt, "The Thai 'Kata Mandiarapala' and Malacca", JSS 55, 2 (1967): 279-86; see pp. 281, 285. Wyatt has accepted this identification as a possibility in the reprinted version of the article; see his Studies in Thai History (Chiang Mai: Silkworm Books, 1994), p. 89, note 21.

(125.) Ming Tai-zong shi-lu, juan 72.4b-5a. 
(126.) Ibid., juan 217.a-b (1419) and 236.4a (1421).

(127.) Ming Xuan-zong shi-lu, juan 76.6b-7a.

(128.) Ming Ying-zong shi-lu, juan 47.4b.

(129.) Ming Tai-zong shi-lu, juan $82.6 \mathrm{a}-\mathrm{b}$.

(130.) Ming Ying-zong shi-lu, juan 132.1b.

(131.) Frankfurter, "Events in Ayuddhya", p. 5. For fuller details of the Ayudhyan campaigns against Lanna, see A.B. Griswold and Prasert na Nagara, "A Fifteenth-Century Siamese Historical Poem", in Southeast Asian History and Historiography -- Essays Presented to D.G.E. Hall, ed. C.D. Cowan and O.W. Wolters (Ithaca: Cornell University Press, 1976), pp. $130-40$.

(132.) Ming Shen-zong ski-lu, juan 394.3b-4a.

(133.) See Vickery, "The Khmer Inscriptions", "Review of 'Thai Titles and Ranks"', "Review of Jeremias van Vliet" (pp. 223-28); Michael Vickery, "Prolegomena to Methods for Using the Ayutthayan Laws as Historical Source Materials", JSS 72 (1984): 37-58, and "On Traibhumikatha", JSS 79,2 (1991): 37-58; B.J. Terwiel, "Ahom and the Study of Early Tai Society", JSS 71 (1983): 42-62; Ishii Yoneo et al., An Index of Officials in Traditional Thai Governments (Kyoto: Kyoto University Centre for Southeast Asian Studies, 1974); Georges

Condominas, L'espace social a propos de l'Asie du Sud-est (Paris: Flammarion, 1980), pp. 475-97; R.B. Jones, Thai Titles and Ranks, including a Translation of Traditions of Royal Lineage in Siam by King Chulalongkorn, (Ithaca: Cornell University Southeast Asia Program, 1971).

(134.) Terwiel, "Ahom and the Study", p. 46.

(135.) Condominas, L'espace social, pp. 483-84.

(136.) Ming Tai-zu shi-lu, juan 68.4b.

(137.) Ibid., juan 94.4b.

(138.) Ibid., juan 102.3a.

(139.) Ibid., juan 68.4b, 85.7b, 117.5b, 164.2a-b, 177.2b. 
(140.) Ibid., juan 101.3a.

(141.) Jones, Thai Titles and Ranks, p. 3; Vickery, "Review of 'Thai Titles and Ranks'", p. 168.

(142.) Condominas, L'espace social, p. 487.

(143.) Ming Tai-zu shi-lu, juan 134.21a.

(144.) Ming Tai-zong shi-lu, juan 56.5a.

(145.) Ming Tai-zu shi-lu, juan 44.3a-b.

(146.) Philip N. Jenner and Saveros Pou, A Lexicon of Khmer Morphology (Mon-Khmer Studies IX-X, Honolulu: University Press of Hawaii, 1980-81), p. 118.

(147.) Ming Thi-zu shi-lu, Juan 68.4b, 85.6b, and 159.1a respectively. "Srisrindara" is not a very satisfying representation of "Si-li Duo-luo-lu", but the titles given in Vickery, "The Khmer Inscriptions" (p. 56, table facing p. 62, and p. 69) and "Review of Jeremias van Vliet" (p. 224), suggest that this is the most likely reconstruction of the title represented by these characters.

(148.) Vickery, "On Traibhumikatha", p. 28; Ming Tai-zu shi-lu, juan $148.1 \mathrm{~b}$.

(149.) Ibid., juan $185.4 \mathrm{a}$ and $34.1 \mathrm{a}-\mathrm{b}$ respectively.

(150.) H.L. Shorto, A Dictionary of the Mon Inscriptions from the Sixth to the Sixteenth centuries (London: Oxford University Press, 1971), P. 57.

(151.) Jones, Thai Titles and Ranks, p.3.

(152.) Vickery, "Review of 'Thai Titles and Ranks"', pp. 169-70.

(153.) G.B. McFarland, Thai-English Dictionary (Stanford: Stanford University Press, 1944), pp. 566-67.

(154.) A.B. Griswold and Prasert na Nagara, "Devices and Expedients: Vat Pa Mok 1727 A.D.", in In Memoriam Phya Anuman Rajadhon, ed. Tej Bunnag and M. Smithies (Bangkok: The Siam Society, 1970), pp. 147-220; see p. 150. See also Vickery, "Review of 'Thai Titles and Ranks"', pp. 
$168-69$.

(155.) Ming Yin g-zong shi-lu, juan 225.11a-b.

(156.) Ibid., juan 344.7b.

(157.) Ming Xiao-zong shi-lu, juan 2.14b.

(158.) McFarland, Thai-English Dictionary, p. 530.

(159.) A.B. Griswold and Prasert na Nagara, "The Asokarama Inscription of 1399 A.D. (EHS No. 2)", JSS 71,1 (1969): 29-56; see p.40. For further examples of the use of "Pu", see Griswold and Prasert, "The Pact", pp. 75, 82; and Michael Vickery, "The Lion Prince and Related Remarks on Northern History", JSS 64,1 (1976): 375.

(160.) Ming Tai-zong shi-lu, Juan 86.4b-5a.

(161.) McFarland, Thai-English Dictionary, p. 577.

(162.) Terwiel, "Ahom and the Study", p. 45.

(163.) Ming Tai-zu shi-lu, Juan 101.3a.

(164.) McFarland, Thai-English Dictionary, p. 452.

(165.) T.W. Rhys Davids and W. Stede, The Pali Text Society's Pali-English Dictionary, Part IV (London: Pali Text Society, 1923), P. 186; Shorto, Dictionary of the Mon Inscriptions, p. 213.

(166.) See for example, Ming Ying-zong shi-lu, juan 113.5b (1444, "Krung Ayudhya") and Ming Xian-zong shi-lu, juan 229.2a (1482, "Krong Phra Nakhon Sri Ayudhya").

(167.) McFarland, Thai-English Dictionary, p. 54; Boeles, "The King of Sri Dvaravati", p. 112.

(168.) Philip Jenner, A Chrestomathy of Pre-Angkorian Khmer, Vol. II (Lexicon of the Dated Inscriptions) (Honolulu: University Press of Hawaii, 1981), p. 24, and Vol. IV (Lexicon of the Undated Inscriptions) (published in 1982), p. 50. Michael Vickery (personal communication) suggests that the "kurung" of old Khmer had ceased to mean a paramount ruler by the time of the first Cambodian inscriptions in the seventh century, and that the term "krung" was used in both Ayudhya and cambodia 
to refer to both the city and also the king. He avers that the terms are likely related.

(169.) Vickery, "Review of 'Thai Titles and Ranks'", p. 168.

(170.) Ming Shen-zong shi-lu, juan 490.3b.

(171.) Suebsaeng, "Sino-Siamese", p. 199.

(172.) Ming Xuan-zong shi-lu, juan 22.2a.

(173.) Charnvit, The Rise of Ayudhya, pp. 81-82.

(174.) Ming Xiao-zong shi-lu, juan 129.1a.

(175.) Ibid., juan 129.2a.

(176.) Ming Tai-zu shi-lu, juan 71.2b-3a, 135.5b and 208.3b.

(177.) Ibid., juan 224.1a.

(178.) Photocopies of the relevant pages from the monograph Phraphuttharup lae phraphim nai kru phraprang Wat Ratburana [Buddha images and votive tablets in the crypt of Wat Ratburana] (Bangkok: Fine Arts Department, 1967) were kindly provided by Charnvit Kasetsiri.

(179.) I am grateful to Bruce Lockhart (personal communication) for clarifying the significance of the MSL account of this event.

(180.) Personal communication from David Wyatt.

Envoys to China from Siam As Recorded in the MSL

Year Name of Envoy

1371 Zhao Yan-gu-man (Chao.....?) [181]

1372 Nai Si-li Chai-lai-shi-xi-ti (Nai Sri......setthi?)

1372 Bao-cai-fu (A title rather than name - See Kobata

and Matsuda p. 151)

1373 Zhao Wei-zhi (Chao ......)

1373 Nai wen-li-luo (Nai...? )

1373 Nai Si-li Chai-la-shi-xi-ti

(As Tai-zu shi-lu 70.1a of 1372)

1374 Nai Zhao Zhan-duo-luo

(Nai Chao Chandra ?)

1374 Po Kun Gang-xin (Po Khun ....?)

1374 Sha-li-ba

1374 Zhao Xi-li Zhi (Chao Sri ...?) 
Po Kun Gang-xin (As Tai-zu shi-lu 86.9b above)

Nai Bao-lun ( Nai ....? )

Zhao Lu Qun Ying (Chao....? )

Zhao Zhi-ban (Chao ...? ?)

Ya-la-er Wen-zhi-li (.....mentri?)

Chen Zi-ren (a Chinese name)

Ban Zhi-san (Ban ....?)

Zhao Lu Nai Ai-guan ( Chao ...?)

Zhao Lu Ba-ai (Chao ....? )

Zhao Yi-ren (Chao ....? )

Mao-luo (Moro?)

Kun Si-li Ji-la-shi-zhi-ti (Khun Sri .... setthi ?)

(Possibly same person as in Tai-zu shi-iu 70.1 a above

Mao-luo (As Tai-zu shi-lu 179.4b above)

Si-li Tan-la-er-si-di (Sri ...setthi) Li Nai-ming (a Chinese name)

Mao-gou (possibly same as Tai-zu shi-lu 179.4b above)

Nai Po-lang-zhi-sbi-ti (Nai ....setthi)

Nai Po-lang-zbi-sbi-ti

Nai Si-wu-luo-zhe (Nai Sivaraja?)

Nai Ai-ji-la (Nai ....?

$\mathrm{Nai} \mathrm{Bi}$ (Nai ...?)

Nai Ai-na-bei-la

Zeng Sbou-xian (a Chinese name)

Nai Po-lang-zhi-shi-ti (As Tai-zu shi-lu 243.3a above)

Nai Bi (Nai ...?) (As Tai-zong shi-lu 34.3 a above)

Hu-du-bu-di-mao-na-na

Nai Po-lang-zhi-shi-ti (As Tai-zu shi-lu 243.3a)

Hu-du-wu-xia-mei (...Mohamed?), and Nai Yi

Nai Shi-lai-zu (Nai ...?)

Kun Wen-kun (Khun Mongkhun?)

Zeng Shou-xian (As Tai-zong $44.3 a$ above)

MSL Reference

Tai-zu shi-lu 68.4b

Tai-zu shi-lu 70.1a

Tai-zu shi-lu $71.2 b-3 a$

Tai-zu shi-lu 85.7b

Tai-zu shi-lu $86.2 b-3 a$

Tai-zu shi-lu 86.4b-5a

Tai-zu shi-lu $86.7 \mathrm{a}-\mathrm{b}$

Tai-zu shi-lu 86.9b

Tai-zu shi-lu $88.4 b-5 a$

Tai-zu shi-lu 94.4b

Tai-zu shi-lu 101.3a

Tai-zu shi-lu 102.3a

Tai-zu shi-lu 115.2a

Tai-zu shi-lu 117.5b

Tai-zu shi-lu $126.5 \mathrm{~b}-6 \mathrm{a}$

Tai-zu shi-lu 135.5b

Tai-zu shi-lu 146.3a

Tai-zu shi-lu 164.2a-b

Tai-zu shi-lu 170.3a

Tai-zu shi-lu 177.2b

Tai-zu shi-lu 179.4b

Tai-zu shi-lu 183.4a

Tai-zu shi-lu 195.2a

Tai-zu shi-lu 197.6b

Tai-zu shi-lu 208.3b

Tai-zu shi-lu 230.5b

Tai-zu shi-lu 243.3a

Tai-zu shi-lu 254.6b

Tai-zu shi-lu 255.5b

Tai-zong shi-lu $23.5 \mathrm{a}$

Tai-zong shi-lu $34.3 a$

Tai-zong shi-lu 36.6a

Tai-zong shi-lu $44.3 a$

Tai-zong shi-lu 48.1 a

Tai-zong shi-lu $52.3 a$

Tai-zong shi-lu 59.3a

Tai-zong shi-lu $72.4 b-5 a$

Tai-zong shi-lu 86.3b

Tai-zong shi-lu 87.3b

Tai-zong shi-lu 97.1b

Tai-zong shi-lu 111.1b

Nai Yi-shi (Nai ...?)

Nai Shi-xian (Nai ...? ) 


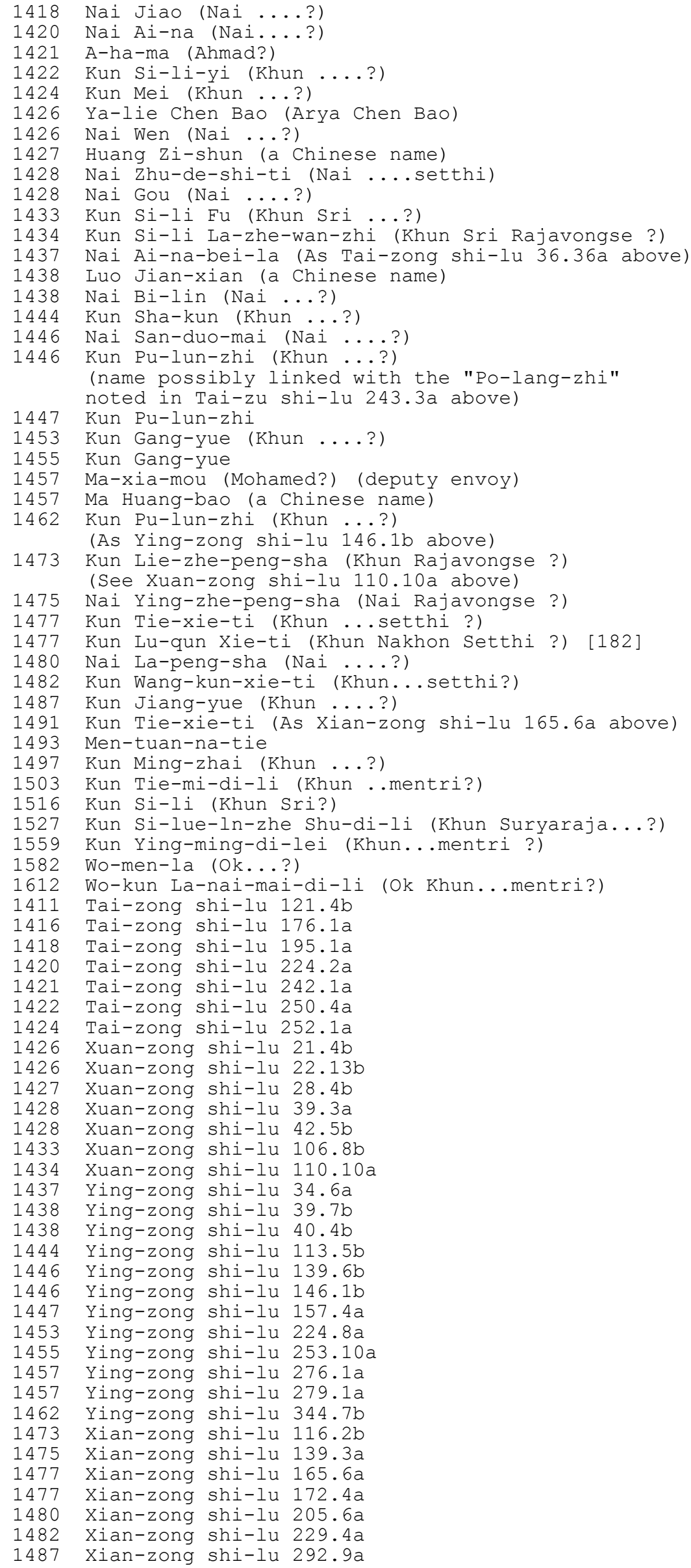


1491 Xiao-zong shi-lu $54.8 \mathrm{a}-\mathrm{b}$

1493 Xiao-zong shi-lu 79.3b

1497 Xiao-zong shi-lu 129.3a

1503 Xiao-zong shi-lu 200.5b-6a

1516 Wu-zong shi-lu 132.7 a

1527 Shi-zong shi-lu $71.11 \mathrm{~b}$

1559 Shi-zong shi-lu 476.3b

1582 Shen-zong shi-lu $125.6 \mathrm{~b}$

1612 Shen-zong shi-lu 490.3b

(181.) Li Dao-gang suggests that this title can be reconstructed as Chao Ai Kuman, meaning "first son of the ruler" ("Can-Lie Bao Bi-Ya", p. 53).

(182.) For a detailed study of the mission by "Kun Lu-qun Xie-ti" and his Chinese deputy Xie Wenbin, see Chan Hok-lam, "Xian-luo gong-shi".

\begin{tabular}{|c|c|c|c|c|c|}
\hline Date & & $\begin{array}{l}\text { Ming shi-Lu References to Si } \\
\text { Precis of Reference }\end{array}$ & $\begin{array}{l}\text { am }(\mathrm{PRE} \\
\text { Ming sh } \\
\text { TAI-ZU }\end{array}$ & $\begin{array}{l}\text { (IS) } \\
\text { i-lu Re } \\
\text { SHI-LU }\end{array}$ & eference \\
\hline 1370, & Aug. 26 & $\begin{array}{l}\text { Court sends envoys to } \\
\text { take proclamation to } \\
\text { country of Siam. }\end{array}$ & Tai-zu & shi-lu & $55.3 a$ \\
\hline 1371, & Oct. 30 & $\begin{array}{l}\text { Envoy sent by Can-lie Zhao } \\
\text { Pi-ya (Somdet Chao Brahya), } \\
\text { king of Siam, } \\
\text { offers tribute at Court. }\end{array}$ & Tai-zu & shi-lu & $68.4 b$ \\
\hline 1372, & Jan. 9 & $\begin{array}{l}\text { Envoy sent by same king } \\
\text { offers tribute. }\end{array}$ & Tai-zu & shi-lu & $70.1 a$ \\
\hline 1372 & Feb. 18 & $\begin{array}{l}\text { Envoy from Siam (Hu) } \\
\text { offers tribute. }\end{array}$ & Tai-zu & shi-lu & $71.2 b-3 a$ \\
\hline 1373, & Oct. 29 & $\begin{array}{l}\text { Envoy sent by Can-lie } \\
\text { Si-ning (Somdet...? ?), } \\
\text { elder sister of king of Siam } \\
\text { (Hu) offers tribute. } \\
\text { Mission refused by Court. }\end{array}$ & Tai-zu & shi-lu & $85.6 b$ \\
\hline $\begin{array}{l}1373, \\
1373\end{array}$ & Nov $\cdot 7$ & Siam envoy offers tribute. & Tai-zu & shi-lu & $85.7 \mathrm{~b}$ \\
\hline 3, & Nov $\cdot 23$ & $\begin{array}{l}\text { Envoy sent by Can-lie } \\
\text { Si-ning again offers } \\
\text { tribute, this time to } \\
\text { Ming empress. Refused. }\end{array}$ & Tai-zu & shi-lu & $86.2 b-3 a$ \\
\hline 1373, & Dec. 7 & $\begin{array}{l}\text { Envoy from Siam (Hu) advises } \\
\text { that Can-lie Zhao Pi-ya has } \\
\text { become incompetent } \\
\text { and that people have } \\
\text { promoted paternal uncle } \\
\text { Can-lie Bao Pi-ya Si-li } \\
\text { Duo-luo-lu to king. }\end{array}$ & Tai-zu & shi-lu & $86.4 b-5 a$ \\
\hline 1374, & $\operatorname{Jan} \cdot 6$ & $\begin{array}{l}\text { Envoy sent by Can-lie } \\
\text { Bao Pi-ya Si-li } \\
\text { Duo-luo-lu, king of Siam } \\
\text { (Hu) offers tribute. }\end{array}$ & Tai-zu & shi-lu & $86.7 a-b$ \\
\hline 1374, & Feb. 10 & $\begin{array}{l}\text { Envoy sent by same king } \\
\text { offers tribute and map } \\
\text { of country. }\end{array}$ & Tai-zu & shi-lu & $86.9 a$ \\
\hline 1374, & May 9 & $\begin{array}{l}\text { Envoy claiming to be } \\
\text { from Siam (Hu) offers } \\
\text { tribute. Refused. }\end{array}$ & Tai-zu & shi-lu & $88.4 b-5 a$ \\
\hline 1374, & Dec. 19 & $\begin{array}{l}\text { Envoy sent by Zhao Lu-qun } \\
\text { Ying, Prince of } \\
\text { Su-men-bang and heir to } \\
\text { king of Siam, offers } \\
\text { tribute. }\end{array}$ & Tai-zu & shi-lu & $94.4 b$ \\
\hline 1375, & Feb. & $\begin{array}{l}\text { Envoy from Siam arrives } \\
\text { to offer tribute }\end{array}$ & Tai-zu & shi-lu & $96.4 b$ \\
\hline 1375, & Mar. 5 & $\begin{array}{l}\text { Ming sacrifices for } \\
\text { mountains and rivers of } \\
\text { Siam appended to those } \\
\text { for Guangxi. }\end{array}$ & Tai-zu & shi-lu & $97.1 \mathrm{a}-\mathrm{b}$ \\
\hline 1375, & DV. 4 & $\begin{array}{l}\text { Envoy sent by king of } \\
\text { Siam offers tribute. }\end{array}$ & Tai-zu & shi-lu & $101.3 a$ \\
\hline
\end{tabular}




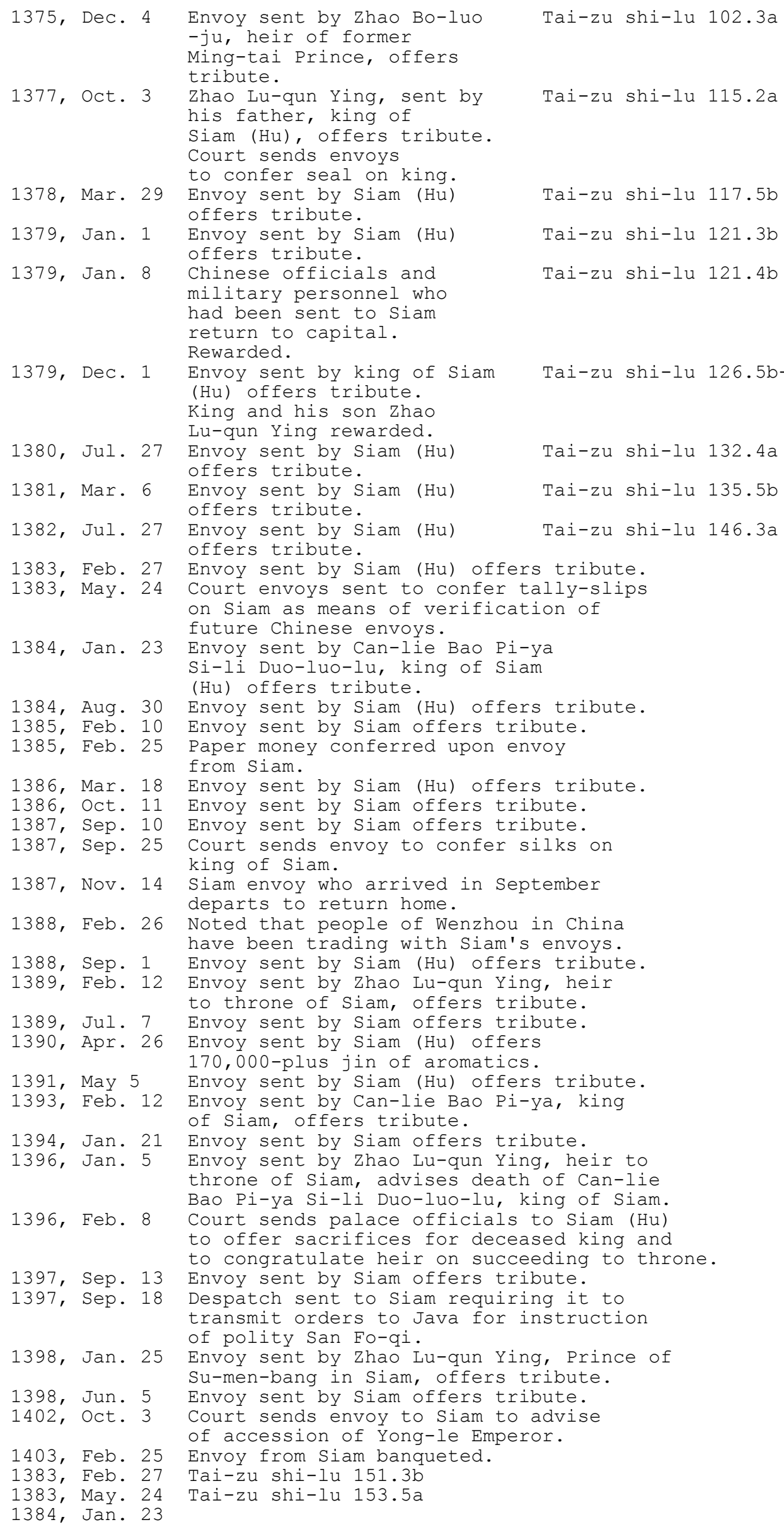


Tai-zu shi-lu 159.1a

1384, Aug. 30

Tai-zu shi-lu 164.2a-b

1385, Feb. 10

1385, Feb. 25

1386, Mar. 18

1386, Oct. 11

1387, Sep. 10

1387, Sep. 25

1387, Nov. 14

1388, Feb. 26

1388, Sep. 1

1389, Feb. 12

1389, Jul. 7

1390, Apr. 26

1391, May 5

1393, Feb. 12

1394, Jan. 21

1396, Jan. 5

1396, Feb. 8

1397, Sep. 13

1397, Sep. 18

1398, Jan. 25

1398, Jun. 5

Tai-zu shi-lu 170.1a

Tai-zu shi-lu 170.3a

Tai-zu shi-lu 177.2b

Tai-zu shi-lu 179.4b

Thi-zu shi-lu 183.4a

Tai-zu shi-lu 184.3a

Tai-zu shi-lu 186.1b

Tai-zu shi-lu 188.3a

Tai-zu shi-lu 193.1a

Thi-zu shi-lu 195.2a

Tai-zu shi-lu 196.4b

Tai-zu shi-lu 201.1b

Tai-zu shi-lu 208.3b

Tai-zu shi-lu 224.la

Tai-zu shi-lu 230.5b

Tai-zu shi-lu 243.3a

Tai-zu shi-lu 243.4b-5a

Tai-zu shi-lu 254.6a

Tai-zu shi-lu 255.5b

Tai-zu shi-lu 256.la

Tai-zu shi-lu 257.4b

TAI-ZONG SHI-LU

1402, Oct. 3

1403, Feb. 25

1403, Feb. 27

Tai-zong shi-lu 12.7a

Tai-zong shi-lu 17.2a

Court sends envoy to Siam to confer seal and

instructions on Zhao Lu-qun Ying-duo-luo-di-la,

king of Siam.

1403, Jul. 1

1403, Aug. 25

1403, Oct. 6

1403, Oct. 10

1404, Oct. 7

Court sends envoy to Siam.

Court sends envoy to Siam.

Envoy from siam rewarded.

Court sends envoy to Siam.

Ship from Siam heading for Ryukyu blown to

Fujian. Emperor orders that the ship be

provided with assistance and sent on.

1404, Oct. 16

Envoy sent by Siam offers tribute. Also

requests conferral of standard Chinese weights and measures.

1404, Nov. 13

1405, Apr. 26

1405, Aug. 7

1405, Oct. 8

1405, Nov. 22

1406, Mar. 21

1406 , Oct. 20

1407, Nov. 20

Envoy sent by king of Siam offers tribute.

Envoy from Siam banqueted.

Envoy from Siam banqueted.

Envoy from Siam rewarded.

Envoy sent by Siam offers tribute.

Envoy sent by Siam offers tribute.

Envoy sent by Siam offers tribute.

Envoy sent by Siam offers tribute. Court notes

that previously Champa envoy to China had

been blown to Pahang by winds. Siam

threatened Pahang and took envoy captive.

Samudera and Melaka had also complained that

Siam had been overbearing and had taken their

seals. At this time, Siam ordered to return envoys and seals.

1408, Sep. 6 Court despatches eunuch to take orders to siam

and return Siamese found in prison in Annam.

Zheng He et al. sent as envoys to Siam, etc.

1408, Oct. 17

1408, Dec. 23

1409, Feb. 5

Envoy sent by king of Siam offers tribute.

Envoy sent by king of Siam offers sacrificial

presents for deceased Ren-xiao Empress.

1409, Nov. 7 Envoy sent by king of Siam offers tribute.

Siam ordered to send Chinese He Ren-guan

and companions back to China.

1410, Dec. 31 Envoy from Siam delivers Chinese wanderers sought by Court. Court sends envoy to Siam.

1411, Nov. 30

Envoy sent by Zhao Lun-qun Ying-duo-luo-di-la,

king of Siam, offers tribute.

1413, Jan. 15

1403, Feb. 27

Envoy sent by king of Siam offers tribute.

Court sends eunuch to confer rewards on him.

rai-zong shi-lu 17.2b

1403, Aug. 25 Tai-zong shi-lu 22.2b

1403, Oct. 6 Tai-zong shi-lu 23.5a

1403, Oct. 10 Tai-zong shi-lu 23.5b

1404, Oct. 7 Tai-zong shi-lu $34.1 \mathrm{~b}-2 \mathrm{a}$

1404, Oct. 16 Tai-zong shi-lu 34.3a

1404, Nov. 13 Tai-zong shi-lu 36.6a 


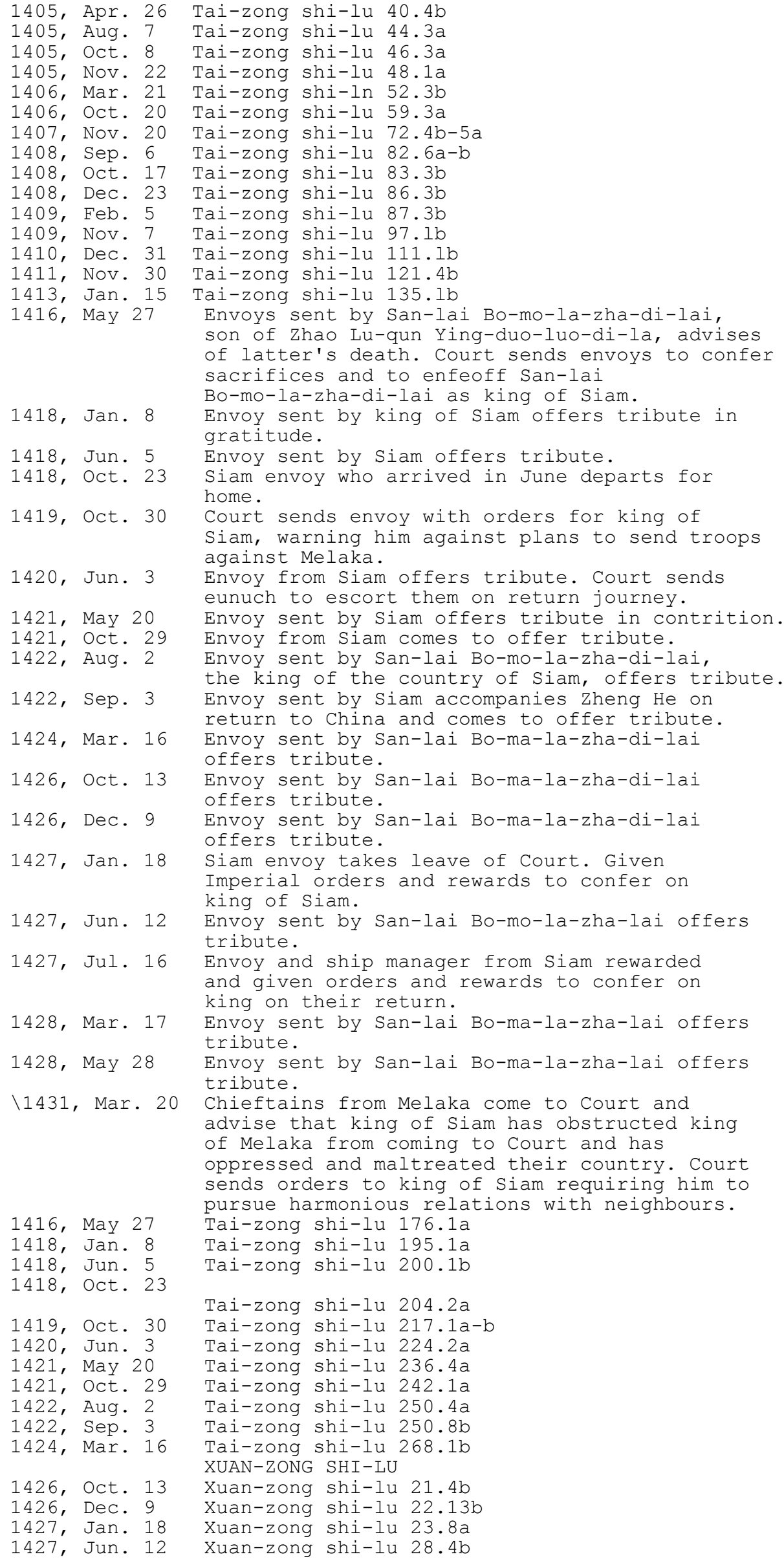




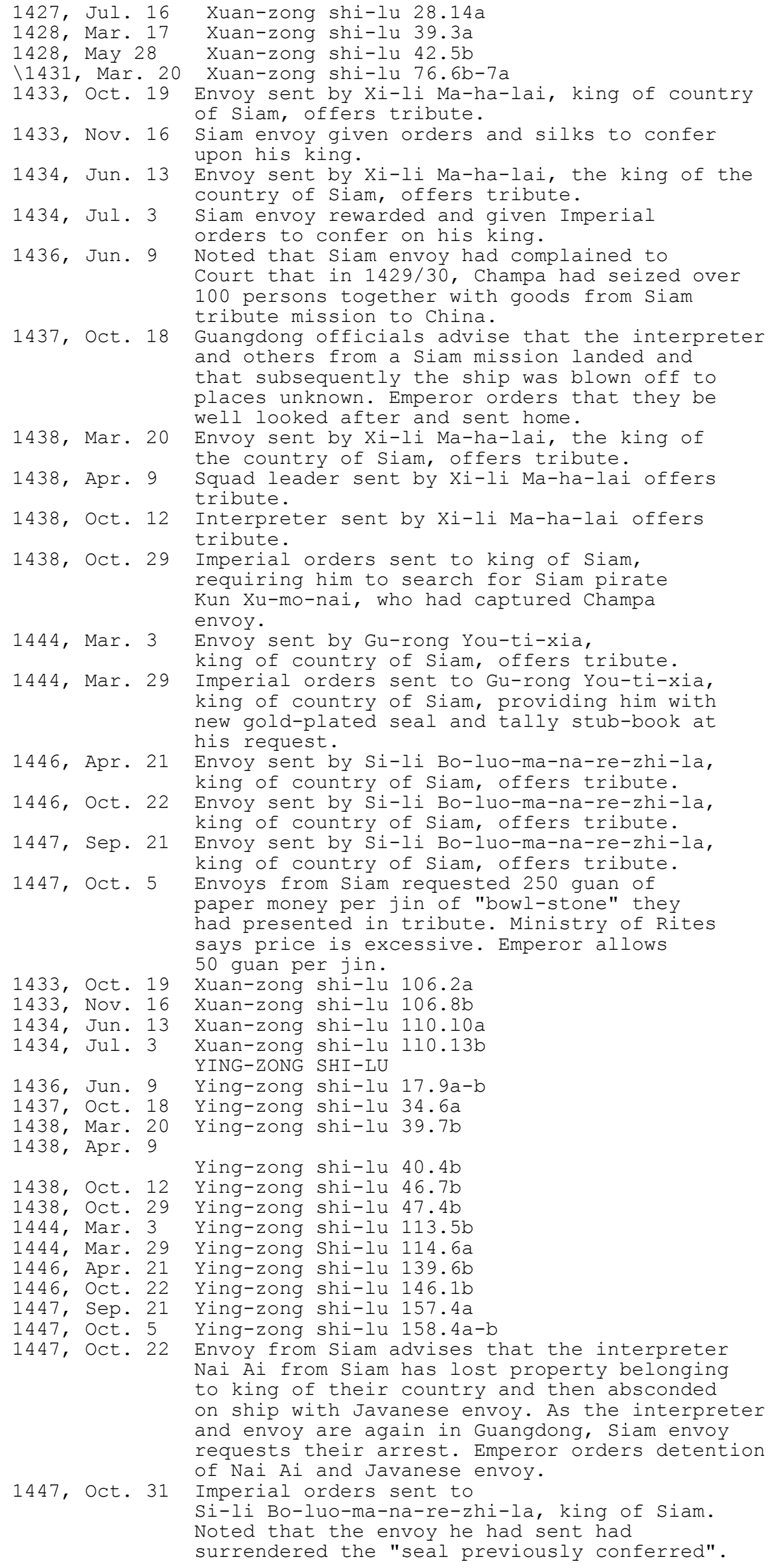


1453, Jan. 19 1453, Feb. 27

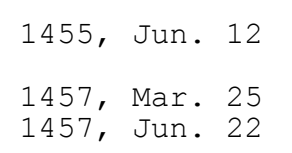

Envoy sent by Siam offers tribute.

Court sends envoys to offer sacrifices for dead king Bo-luo-mo-la-zha-di-la and to enfeoff son Ba-luo Lan-mi-sun-la as king of Siam.

Envoy sent by Ba-luo Lan-mi-su-la, king of country of Siam, offers tribute.

Envoy sent by Siam rewarded.

Officials report that envoy from Siam has been purchasing children in China from starving farmers to take back to Siam as servants. Requests that the children be re-purchased to maintain China's dignity. Approved.

Envoy sent by Bei-la Lan-luo-zhe-zhi-bo-zhi, king of Siam, offers tribute.

Noted that person from Fujian had gone to country of Siam and claimed to be envoy of court. His wife also had audience with wife of king. On return to China, he was captured and executed.

Envoy sent by country of siam offers tribute. Requests replacement of tally-slips and tally stub-book which had been issued in Tian-shun reign, due to their having been damaged by insects.

Envoy sent by Siam offers tribute. Imperial orders sent back to Siam with him.

Envoy sent by Siam offers tribute.

Deputy envoy sent by Siam offers tribute.

Envoy sent by Siam requests ships to replace those damaged on forward journey. Approved by emperor, but subsequently Siam envoys memorialize that Guangdong officials had demanded valuables.

Ying-zong shi-1u $158.4 \mathrm{a}-\mathrm{b}$

Ying-zong shi-lu $158.8 \mathrm{a}$

Ying-zong shi-lu 224.8a

Ying-zong shi-lu 225.1la-b

Ying-zong shi-lu 253.10a

Ying-zong shi-lu 276.1a

Ying-zong shi-lu 279.1 a

Yin-zong shi-lu $344.7 \mathrm{~b}$

XIAN-ZONG SHI-LU

Xian-zong shi-lu $97.7 \mathrm{~b}$

Xian-zong shi-lu 116.2b

Xian-zong shi-lu 139.3a

Xian-zong shi-lu 165.6a

Xian-zong shi-lu 172.4a

Xian-zong shi-lu 192.3a-b

Envoy sent by siam offers tribute.

Envoy from Siam requests that his ship be repaired and that dragon robes be conferred upon his king. Approved by emperor.

Noted that envoys from Siam purchased children in China on their return journey. Children redeemed by officials and instructions made known

forbidding such purchases.

Envoy sent by country of Siam offers tribute.

Court sends envoys to take proclamation to Siam enfeoffing Guo-long Bo-la Lue-kun Si-li You-di, heir to the king, as king of the country.

Envoy sent by king of country of Siam offers tribute.

Envoy sent by Guo-long Bo-la Lue-Kun Xi-li You-di-ya, king of Siam, offers tribute. Envoy advises that as there were differences between the memorial requesting enfeoffment and the issued tally-slips, the king suspected his scribes of fraud. Ming court orders that, to 
prevent further abuses, only

Arabic script is to be used in

future memorials.

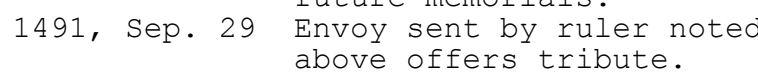

1493, oct. 1 Envoy sent by king of Siam

offers tribute.

1495, Sep. 29 Six persons from Siam blown to

Hainan. Ordered that they be

provided with food and that

they be sent back with next

returning envoy.

1497, Sep. 28 Interpreter sent by country of

Siam advises that he was

originally from Fujian in

China. Requests permission to

visit family graves on way back

to Siam. Approved.

1497, oct. 2 Interpreter from Siam advises

that he was originally from

Jiangxi in China. Requests that

he be allowed to remain in

China as an interpreter at

capital.

1497, Oct. 9 Envoy sent by Guo-long Bo-la-lue

Kun Xi-li You-di-ya, king of

Siam, offers tribute.

1497, oct. 12 Siam presents memorial but

Translators Institute has no

department specialized in

translation of siamese script.

Thus despatch sent to Guangdong

requiring it to seek out persons

with knowledge of Siam's language and script.

1480, Sep. 1 Xian-zong shi-lu 205.6a

1480, Sep. 15 Xian-zong shi-lu 206.2b

1481, Aug. 19 Xian-zong shi-lu $217.4 \mathrm{a}$

1482, Jul. 27 Xian-zong shi-lu 229.4a

1482, Jul. 28 Xian-zong shi-lu $229.4 \mathrm{a}$

1487, Aug. 11 Xian-zong shi-lu 229.9a

1487, Sep. 30 XIAO-ZONG SHI-LU

Xiao-zong shi-1u 2.140

Xiao-zong shi-lu $54.8 \mathrm{a}-\mathrm{b}$

1493, Oct. 1 Xiao-zong shi-lu 79.3b

1495, Sep. 29 Xiao-zong shi-lu 104.2a

1497, Sep. 28 Xiao-zong shi-lu 129.1a

1497, Oct. 2 Xiao-zong shi-lu 129.2a

1497, Oct.9 Xiao-zong shi-lu 129.3a

1497, Oct. 12 Xiao-zong shi-lu 129.3b

1501, May 20 A replacement set of Hong-zhi reign tally-slips conferred upon Siam to replace those destroyed in a fire.

1503, Jul. 6 Envoy sent by king of Siam offers tribute. Ministry of Rites notes gross violation of propriety as despatch sent to Ministry of Rites signed by Pu-ba-lazhi-cha, an official of the Palace Service Department in Siam. Requests permission to send despatch to king advising him that he must sign all despatches personally. Approved.

1504, Dec. 11 Noted that previously a servant of the eunuch director Wang Jing of Guangdong had stolen goods of envoy from siam. As envoy is about to return home, Emperor allows payment of silver in compensation for goods stolen.

1505, Jul. 17 Noted that previously when Lin Xiao sent as Chinese envoy to Siam, king refused to face North or follow Chinese rites. Lin Xiao secluded and died of hunger.

1509, Mar. 23 Ships from Siam had been blown offcourse and had anchored in Guangdong. Local request to court for permission to tax their cargoes was refused.

1516, Jan. 25 Chief envoy from Siam requests silver 
from court to repair ships for homeward journey. Guangdong ordered to provide silver for this purpose.

1521, Aug. 21 Ordered that Siam be instructed to assist people from Melaka, whose territory had been seized by the Portuguese.

1527, Jan. 31 Envoy from Siam offers tribute.

1536, Oct. 13 Guangdong ordered to seek medicinal materials in coastal areas of Siam.

1554, oct. 20 Envoys sent by Bo Lue-kun Xi-li

You-chi-ya (Phra Nakhon Si Ayudhya), king of Siam, offer tribute.

1558, Sep. 4 Envoy sent by same ruler offers tribute.

1559, Oct. 17 Envoy sent by same ruler offers tribute.

1501, May 20 Xiao-zong shi-lu 174.2a

1503, Jul. 6 Xiao-zong shi-lu 200.5b-6a

1504, Dec. 11 Xiao-zong shi-lu 218.4a-b

WU-ZONG SHI-LU

1505, Jul. 17 Wu-zong shi-lu 2.18b-19b

1509, Mar. 23 Wu-zong shi-lu 48.1b-2a

1516, Jan. 25 Wu-zong shi-lu 132.7a

1521, Aug. 21 Shi-zong shi-lu 4.27b

1527, Jan. 31 Shi-zong shi-lu 71.11b

1536, Oct. 13 Shi-zong shi-lu 191.13b

1554, Oct. 20 Shi-zong shi-lu 414.8a

1558, Sep. 4 Shi-zong shi-lu 462.4b

1559, oct. 17 Shi-zong shi-lu 476.3b

1567, Mar. 13 Envoy sent by Hua-zhao-song

(Alt: Hua-tai-song or Hua-zhao-zhu),

the king of Siam, advises that the seal and tally-slips provided by the Ming Court have been destroyed in attack by country of Dong-niu (Toungoo).

1575, Jul. 9 Country of Siam offers tribute.

1575, Jul. 24 Replacement of Siam's seal and tally-slips approved.

1578, Oct. 11 Noted that previously Chinese pirate Lin Dao-qian had attacked the "black-raven" ships of the country of Siam, but had been beaten off.

1578, Nov. 6 Seal cast and supplied to king of Siam.

1578, Dec. 8 Noted that Siam Department has recently been established in Translators Institute in Beijing.

1580, May 26 Noted that Chinese pirate Lin Dao-qian has been attacking Siam and threatening Patani and that those two places wish to assist in his capture. Reward for his capture posted.

1580, oct. 3 Noted that Lin Dao-qian left Siam some time previously.

1582, Jul. 11 King of country of Siam issued with seal. 1591, Jul. 1 Noted that Burma has attacked Yunnan. Emperor orders that Niu-da-la of Siam be required to mount pincer attack on Burma.

1592, Oct. 31

1592, Nov. 16

1593, Feb. 6

Tribute envoys from Siam banqueted.

Envoys from Siam offer tribute.

Noted that tribute envoy from Siam has offered that country's naval forces to help

Chinese fight against Japanese in Korea. Chinese debate propriety of using foreign forces. King of Siam ordered to ready ships.

1601, Mar. 5 Noted that some envoys from Siam have remained in Guangdong.

1604, Apr. 12 Noted that Burma has attacked Meng Nai and that Meng Nai and Siam have entered an alliance to oppose Burma. China sends persons to Siam to arrange combining of forces.

1612, Jan. 25 Envoy sent by Pu-ai, king of the country of Siam, presents memorial.

1617, Nov. 25 Country of Siam presents memorial and 14,800 jin of local products in tribute. SHEN-ZONG SHI-LU

1567, Mar. 13 Shen-zong shi-lu 11.2a

1575, Jul. 9 Shen-zong shi-lu 39.la

1575, Jul. 24 Shen-zong shi-lu 39.7b 


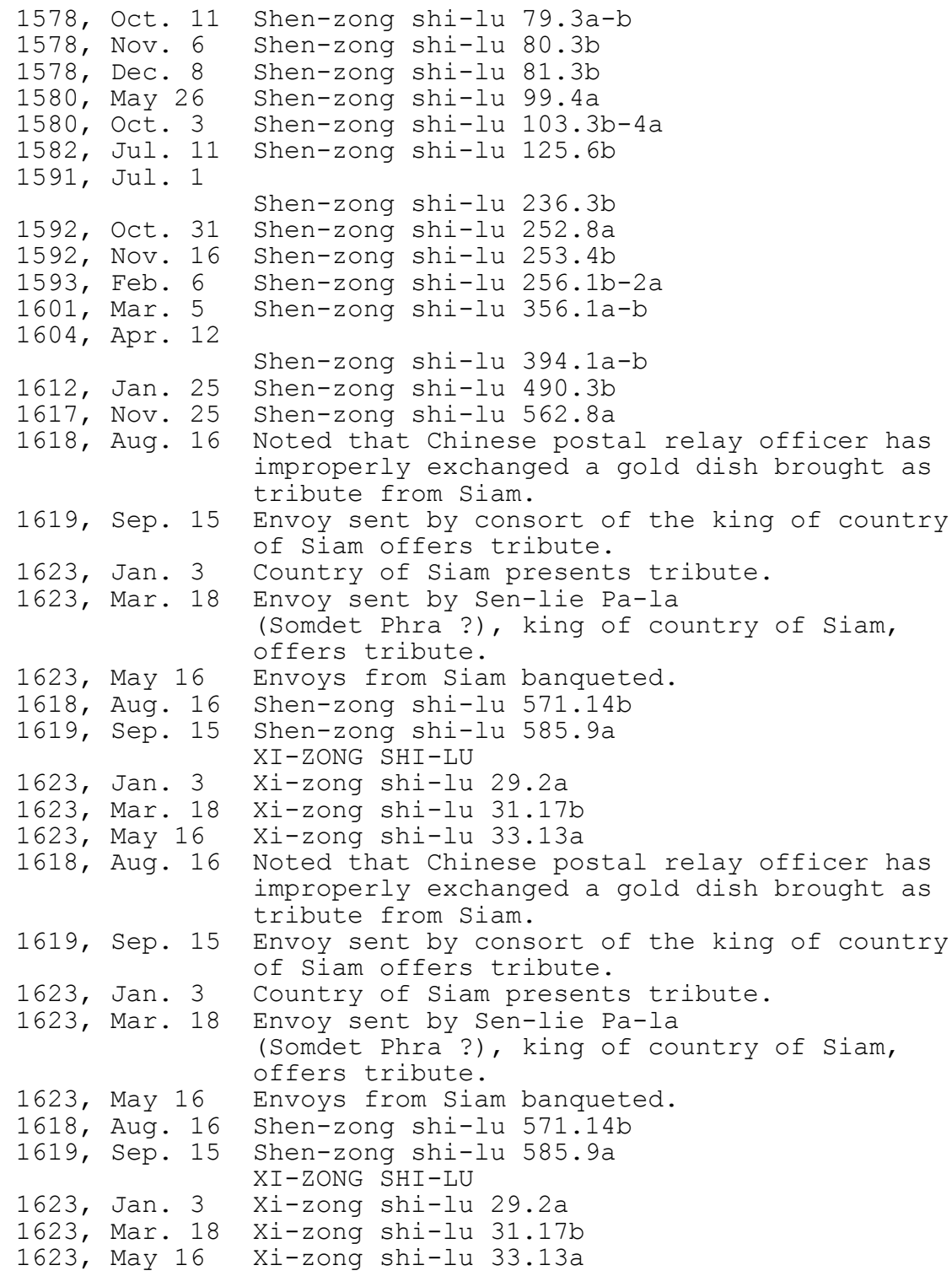

Note: The terminology employed in this precis is that used in the Ming shi-lu references. Therefore, references to the offering of "tribute", imperial "approval", requests for "enfeoffment", and so on, reflect only ideas and categories contained within the chinese texts.

\section{FULL TEXT}

Document jsas000020010807dw910001e 